\title{
A REVIEW OF THE LITERATURE RELATING TO THE CRITICAL CONSTANTS OF VARIOUS GASES
}

\author{
By S. F. Pickering
}

\begin{abstract}
This review of the literature on the critical constants of various gases is an attempt to include all of the available data on the more common gases and to select what appear to be the best values. A short description of the nature of the phenomena occurring at the critical point and of the usual methods of determining the critical constants is given, after which the measurements on the various gases are critically discussed. In selecting the final value the precautions taken in the preparation and purification of the gas in question, the methods used in making the determinations, and the agreement between the results of different observers have all been given careful consideration.
\end{abstract}

\section{CONTENTS}

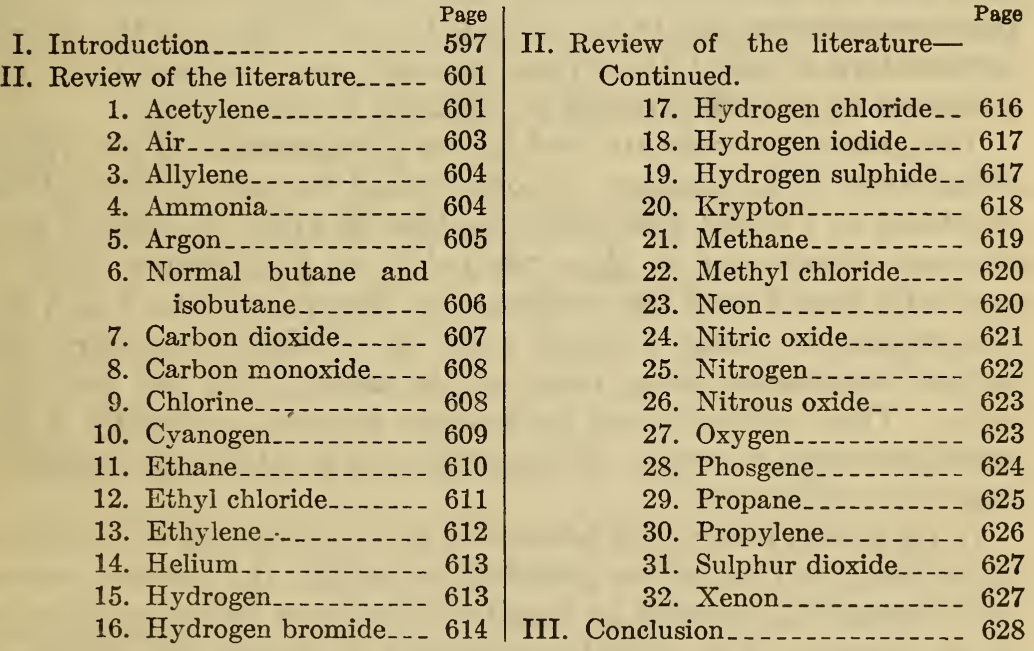

\section{INTRODUCTION}

In the following review of the literature on the critical constants of gases an attempt has been made to include all of the available data on the more common gases and, as far as possible, to select what appear to be the best values. In each case the reasons governing the selection are stated. The results selected are for convenience assembled in a table at the end of the paper.

Only the more recent determinations have been critically considered, because it is thought that the methods of purifying the 
gases and of making the measurements employed by the earlier observers were not sufficiently developed to justify their comparison with the more modern methods. These determinations involve many experimental difficulties, and the technique of making them has been materially improved in recent years. In a number of cases, however, the results obtained even by recent contemporary observers do not agree, and it is therefore often impossible to select values with certainty.

The critical temperature of a substance may be defined as the minimum temperature above which the substance can not be liquefied, no matter how great the pressure. If the temperature of a substance is raised toward its critical temperature, the density of the liquid phase becomes gradually lower and that of the saturated vapor phase becomes gradually higher. Near the critical temperature the meniscus separating the two phases begins to flatten and finally disappears when the critical temperature is reached. At this temperature the physical properties of the two phases become identical and all distinction between gas and liquid disappears. The pressure corresponding to the saturated vapor pressure at the critical temperature is called the critical pressure, and the density of the substance at this critical point is called the critical density.

Two general methods are used for the determination of the critical temperature of a substance. In one method the right amount of the substance in a sealed glass tube (the tube in which the critical phenomena are observed is often referred to as a laboratory tube) is gradually heated until the meniscus just disappears, after which the temperature is slowly lowered until the meniscus reappears, the critical temperature being taken as the mean of the two temperatures. This method is not particularly accurate, especially if the substance contains traces of impurities which retard the establishment of equilibrium. ${ }^{1}$

In the second method the laboratory tube is connected to a suitable manometer, and means are provided for varying the pressure. It is very desirable to provide an agitator in order to insure equilibrium of the sample. The critical temperature is usually taken as that temperature at which a very slight decrease in pressure causes the meniscus to temporarily appear until the temperature of the substance reestablishes itself. This method is used by most of the observers, although in some instances the critical point is determined in a somewhat different manner. For example, Onnes determined the critical constants of neon and of hydrogen by making a series of pressure measurements at constant temperature, the range of these measurements including that wherein condensation occurs. The volumes of liquid condensed were also determined. A series of such

1 Kuenen, Comm. Leyden No. 8. 
isothermals was obtained, starting with temperatures slightly below the critical temperature. From these data the critical temperature and pressure were calculated. (See discussion of hydrogen.)

Cardoso ${ }^{2}$ in the case of gases other than the so-called permanent gases, used the disappearance of the critical opalescence as a criterion of the critical temperature. The critical opalescence, according to Cardoso and others, is caused by the formation, at temperatures slightly below the critical temperature, of a sort of emulsion of the vapor and liquid phases which have approximately the same density. These minute drops of liquid disappear at the critical temperature.

According to an alternative explanation, the critical opalescence arises from the unequal distribution of molecules which occurs at the critical temperature. At this temperature the velocities of the molecules vary widely, and at different points even slightly above the critical temperature there may be momentary associations of slowly moving molecules. Because of their slower motions, the temperatures of these momentary minute aggregates would be slightly lower, and while they would immediately be dispersed, others would form and thus give an opalescent appearance to the substance. According to this explanation the opalescence might appear at temperatures above the critical, in which case most of Cardoso's values for the critical temperatures of the more easily liquefied gases would be slightly high.

This question has been discussed quite extensively by various authors ${ }^{3}$ but has not been definitely settled as yet.

Since the critical pressures as measured by the various observers correspond to their respective critical temperatures, and since temperature and vapor pressure are intimately related, the values for the critical pressure of a given gas should be corrected to correspond to the value chosen for the critical temperature.

Such corrections, when significant, are made by means of van der Waal's equation connecting vapor pressure with temperature. This equation is $\log \frac{P_{\mathrm{c}}}{p}=f\left(\frac{T_{\mathrm{c}}-T}{T}\right)$, where $P_{\mathrm{c}}$ and $T_{\mathrm{c}}$ are the critical pressure and critical temperature, respectively, and $p$ is the pressure corresponding to temperature $T$, the temperatures being expressed on the absolute scale. Taking $T_{\mathrm{c}}-T$ to be $1^{\circ}$, the equation thus becomes $\log \frac{P_{\mathrm{c}}}{p}=\frac{f}{T}$.

2 Cardoso, J. chim. phys., 10, p. 491; 1910.

${ }^{2}$ Einstein, Ann. Physik., 10, p. 491; 1905. Travers and Usher, Proc. Roy. Soc. (London), 78, p. $247 ; 1906$. Young, "Stoichiometry," p. 172; 1908. Onnes and Keesom, Comm. Leyden No. 104. Young, Phil. Mag., November, 1910. Smoluchowski, Bull. Acad. des Sc. de Cracovie, December, 1907; Ann. Physik., 25, p. 205; 1908; Trans. Roy. Soc. London A, 212, p. 165; 1912. Rothmund, Z. physik. Chem., 26, p.433; 1898; 63, p. 54; 1908. Ostwald, Añ. Physik., 4, p. 35; 1912. Küster, Lehrbuch der physikalischen Chemie, p. 1907. 
The values for $f$, which vary from 2.1 to 3.0 for the different gases, have been chosen to conform to the table given by Lewis. ${ }^{4}$

An example of this method of correction as applied to acetylene is as follows:

$$
\begin{aligned}
& \log \frac{P_{\mathrm{c}}}{p}=\frac{3}{309}=0.01 \\
& \therefore \frac{P_{\mathrm{c}}}{p}=1.02
\end{aligned}
$$

taking $P_{\mathrm{c}}$ equal to $62.0 \mathrm{~atm}$., $p$ becomes $60.8 \mathrm{~atm}$.

$$
62.0 \mathrm{~atm} .-60.8 \mathrm{~atm} .=1.2 \mathrm{~atm} .
$$

The correction is therefore 1.2 atmospheres per degree.

After selecting $309^{\circ}$ for the critical temperature, the values for the critical pressure were corrected to this temperature, the final result being given to the nearest whole atmosphere because of the doubt concerning the accuracy of the critical temperature.

Because of the extreme compressibility of substances near their critical points it is very difficult to directly determine the critical density accurately. In fact, the density of a substance at its critical point is not uniform because the pressure varies at different levels. The weight of the substance itself gives rise to a slightly greater pressure at the lower end of the container. Grey ${ }^{5}$ states that in a tube $10 \mathrm{~cm}$ in height containing pure carbon dioxide at its critical point there may be a difference of 6 per cent between the densities at top and bottom.

The method for determining critical densities devised by Cailletet and Mathias ${ }^{6}$ probably yields the most accurate results. According to this method a series of observations of the densities of the liquid and vapor phases is made at different temperatures below the critical temperature and extending nearly to it.

These determinations of densities when plotted graphically against the termprature give a curve resembling a parabola. If one then plots a series of points representing the means of the densities of the two phases at the same temperatures, a straight line is obtained for most gases. This line is called the rectilinear diameter of the substance, and if the equation of the line in terms of the temperature is obtained the critical density is given by substituting in this equation the value for the critical temperature, for at this temperature the densities of the two phases become equal to each other and to the mean density. The rectilinear diameter, therefore, intersects the critical temperature ordinate at the point designating the critical density. For some gases, particularly those having a very high critical

1 Lewis, A System of Physical Chemistry, 1, p. 95; 1920.

- Grey, Compt. rend., 115, p. 720; 1892.

- Cailletet and Mathias, Compt. rend., 102, p. 1202; 1856. 
temperature, the rectilinear diameter has a slight curvature near the critical temperature, but in most cases it may be considered a straight line.

There are several methods for determining the densities of the liquid and saturated vapor phases, but their descriptions are rather lengthy and involved and so can not be properly included in this paper. These methods have been employed with some differences in detail by Mathias, ${ }^{7}$ Amagat, ${ }^{8}$ Young, ${ }^{9}$ and Young and Thomas, ${ }^{10}$ while good descriptions of the methods and of the critical phenomena in general are to be found in Young's "Stoichiometry," 11 and in "Le point critique des corps purs" (Paris, 1904), by Mathias.

For the critical data of substances not herein mentioned the reader is referred to the various tables of physical and chemical constants. Van Laar ${ }^{12}$ has published a table containing the critical constants of a great many substances, including a large number of organic compounds. The values are selected from different tables and from the results of certain investigators. When one considers, however, the disagreement between observers regarding the critical constants of the more common and more easily prepared substances, it becomes apparent that the data in the above-mentioned tables are only approximate, being based in many cases upon the work of but one observer.

In the following tables the temperatures are given in degrees centigrade, the pressures in atmospheres, and the densities in grams per cubic centimeter. An asterisk placed before a value indicates that this author did not state how the values were obtained, while parentheses indicate that the inclosed figures were calculated from other physical properties. The figures followed by a question mark are considered unreliable.

\section{REVIEW OF THE LITERATURE}

\section{ACETYLENE}

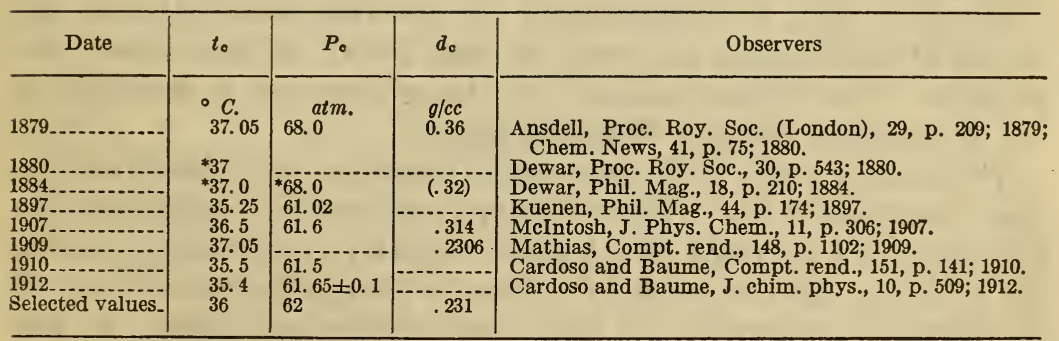

7 Mathias, Ann. de Toulouse, 5, 1891.

8 Amagat, Compt. rend., 114, p. 1093; 1893.

' Young, J. Chem. Soc., 59, p. 37; 1891. Phil. Mag., 33, p. 503; 1892.

10 Young and Thomas, Trans. Chem. Soc., 63, p. 1199; 1893.

11 Young, "Stoichiometry," p. 160; 1908.

13 Van Laar. Proc. Acad. Sci. Amsterdam, 18, II, p. 1224; 1916. 
The recent determinations of the critical pressure of acetylene are quite concordant, but those of the critical temperature differ markedly.

All of the observers mentioned prepared acetylene from calcium carbide and water. McIntosh purified the gas by washing with sodium hydroxide and with chromic acid, after which it was dried with concentrated sulphuric acid and phosphorus pentoxide and then solidified. As the manometer was calibrated to 40 atmospheres only, there is some doubt as to the accuracy of the value for the critical pressure. The acetylene was not agitated while the observations were being made.

Mathias after removing phosphine and stibine from the acetylene dried the gas over calcium chloride, passed it through several bulbed tubes maintained at $-79^{\circ} \mathrm{C}$. and then solidified it by means of liquid air. The two laboratory tubes in which the critical phenomena were observed were rinsed out 17 times with fresh portions of acetylene and evacuated after each rinsing. The whole apparatus, including the tubes of solidified acetylene, was then evacuated to a fraction of a millimeter, after which five portions of the acetylene were evaporated and removed by evacuation. The samples used in the measurements of the densities were finally condensed and sealed in tubes. Mathias gives no details regarding his method of determining the critical temperature.

Cardoso and Baume bubbled acetylene through potassium permanganate and potassium hydroxide solutions and dried it with phosphorus pentoxide. The acetylene was then fractionally disiilled 8 or 10 times and introduced into the laboratory tube, which had been previously exhausted by a mercury pump.

Kuenen's sample contained traces of impurity, while those of McIntosh and of Cardoso and Baume were quite pure, as indicated by the fact that the pressure remained practically constant when the gas was condensed at constant temperature.

It seems best, in consideration of the differences between the results of the different observers, to take $36^{\circ} \mathrm{C}$. as the critical temperature. The critical pressure after being corrected as described in the introduction becomes 62 atmospheres.

The method which McIntosh used to determine the critical volume (the reciprocal of the critical density) consisted in introducing the gas into a tube provided with a sealed capillary at the top and noting the volume at the critical point. Some of the capillary was drawn off by means of a blowpipe and the volume determined again. In this way several tubes were prepared which were almost exactly filled at the critical point. These tubes containing the acetylene were weighed and the critical densities calculated. The mean of the values so obtained was 0.314 . This method, however, is inaccurate because 
of the great compressibility of the substance at its critical temperature and is inferior to the method used by Mathias, as stated in the general discussion of the determination of the critical density.

By substituting $310.15^{\circ}$ absolute, his own value for the critical temperature, into the equation for the rectilinear diameter of acetylene Mathias obtained 0.2306 for the critical density. If, instead, $309^{\circ}$ absolute is used, the critical density becomes 0.2313 .

\section{AIR}

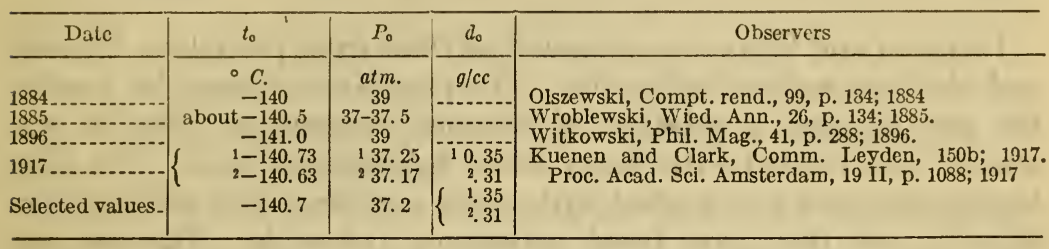

1 "Plait-point."

2 "Critical point of contact."

Wroblewski observed that near its critical region air behaves differently from other substances. This he ascribed to the fact that air is a mixture, although Kuenen and Clark state that the anomalous phenomena which he describes were largely due to insufficient mixing.

It is quite difficult to make determinations of the critical constants of air because of the fact that as mercury can not be used directly for varying the pressure at these low temperatures and in its place the air itself is connected by means of a capillary tube to the outside measuring apparatus, the air fractionates to some extent through the capillary and leaves the residue richer in oxygen, unless special care is used.

In the case of certain binary mixtures there are, according to Kuenen, ${ }^{13}$ two critical points, the "critical point of contact" and the "plait point." The temperature at the "critical point of contact" corresponds to the critical temperature of a pure substance as defined in the first part of the paper in that this temperature is the highest at which liquid can exist at any pressure. The liquid phase just below this temperature differs from the vapor phase both in composition and density. At a slightly lower temperature the densities of the liquid and vapor phases become equal and the critical phenomena appear. This point is called the "plait point."

Kuenen and Clark, however, do not make themselves entirely clear in this respect, inasmuch as their data and curve indicate that the densities are equal at the "critical point of contact" and not at the "plait point." The air which these observers used was free from water vapor and carbon dioxide. The pressures were measured in a closed hydrogen manometer, while two platinum resistance thermometers were use for temperature measurements.

${ }^{13}$ Kuenen, Comm. Leyden No. 4; 1892.

$6848^{\circ}-26-2$ 
The density determinations were somewhat irregular and are considered uncertain.

\section{ALLYLENE}

\begin{tabular}{|c|c|c|}
\hline Date & $t_{0}$ & Observers \\
\hline Selected value & $\begin{array}{l}{ }^{\circ} \mathrm{C} . \\
129.5 \\
127.9 \\
128\end{array}$ & $\begin{array}{l}\text { Lespieau and Chavanne, Compt. rend., 140, p. 1035; } 1905 \\
\text { Maass and Wright, J. Am. Chem. Soc., 43, p. 1078; } 1921 .\end{array}$ \\
\hline
\end{tabular}

Lespieau and Chavanne prepared allylene from propylene bromide and alcoholic sodium hydroxide. The precipitate formed by passing the gas through a solution of cuprous ammonium chloride was washed and treated with warm dilute hydrochloric acid. The allylene so obtained was washed with water and dried first over calcium chloride and then over fused potassium hydroxide. The gas was then passed through a bulbed tube maintained at $-23^{\circ} \mathrm{C}$. The allylene was then solidified and any residual gas removed by evacuation. A part of the allylene was distilled into another tube and used for the determination. The purity of this sample was somewhat questionable, especially in view of the fact that the purity was checked by measuring the volume changes occurring when $2.5 \mathrm{cc}$ of the allylene was exploded with air and the carbon dioxide produced was absorbed with potassium hydroxide. The critical temperature was taken as the lowest temperature of appearance or disappearance of an image formed by reflection on the surface of the liquid inclosed in a sealed tube.

The details of the method used by Maass and Wright for the preparation of allylene are to be published in connection with another investigation. Exceptional purity, however, is claimed for the samples used, and preference is given to the value obtained by these authors.

\section{AMMONIA}

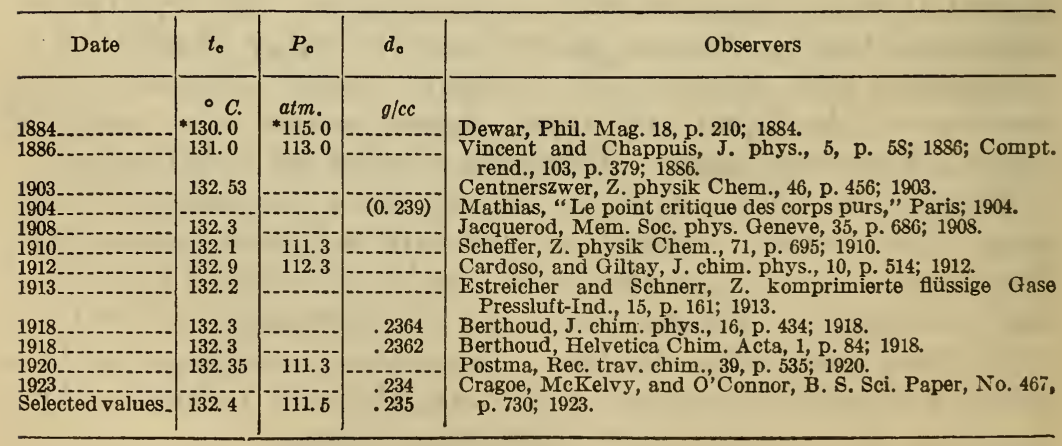


Centnerszwer and the later observers have agreed fairly well on the critical temperature of ammonia, excepting, perhaps, Cardoso and Giltay, whose result is a little higher than the others. All of the observers took great care in the purification of their samples, and there is no one observer to whose work a preference can be given. It therefore seems best to average the results for the critical temperature extending as far back as that of Centnerszwer.

The change of vapor pressure of ammonia calculated by the equation of van der Waals, as mentioned in the introduction, is 1.9 atmospheres per degree. The three more recent determinations of the critical pressure, after being corrected to the value for the critical temperature, are $111.9,111.4$, and 111.3 atmospheres, the mean being 111.5 atmospheres.

Berthoud measured the densities of the liquid and vapor phases, using the method of Young modified by Ter Gazarian. ${ }^{14}$ The apparatus consisted of two calibrated capillary tubes about $25 \mathrm{~cm}$ in length, each provided with a small bulb at the lower end. The bulbs were one-fourth and one-third the total volumes of the tubes. Both tubes were mounted together in a suitable bath. Known weights of ammonia were placed in the tubes, and the volumes of the liquid and vapor were measured at various temperatures. The value for the densities of the two phases when equal was taken as the critical density.

Cragoe, McKelvy and O'Connor used three carefully calibrated picnometers of different sizes in their direct measurements of the densities of the liquid and the saturated vapor. They also determined the densities of the saturated vapor by an optical method. This method makes use of the relation between the density and the refractivity of a substance. The refractivities were measured by means of a Fizeau-Pulfrich interferometer. The critical density was calculated from the equation for the mean diameter.

The value selected for the critical density is the mean of the determinations of Berthoud and of Cragoe, McKelvy, and O'Connor.

\section{ARGON}

\begin{tabular}{|c|c|c|c|c|}
\hline Date & $t_{0}$ & $P_{0}$ & $d_{\mathrm{o}}$ & Observers \\
\hline 1895 & $\begin{aligned} & \circ \circ . \\
&-121.0 \\
&-117.4\end{aligned}$ & $\begin{array}{l}\text { atm. } \\
50.6 \\
52.9\end{array}$ & $g / c c$ & $\begin{array}{l}\text { Olszewski, Trans. Roy. Soc. London (A), 186, p. } 253 ; 1895 . \\
\text { Ramsay and Travers, Trans. Roy. Soc. London (A), } 197, \text { p. }\end{array}$ \\
\hline 1910 & -122.44 & 47. 996 & $\begin{array}{l}1 \\
\stackrel{1}{0} .509 \\
2.53078\end{array}$ & $\begin{array}{l}\text { Crommelin, Comm. Leyden Nos. 115, 118a; } 1910 . \\
\text { Mathias, Onnes, and Crommelin, Comm. Leyden. No. } \\
\text { 131a; 1912. Proc. Acad. Sci. Amsterdam, 15 II, p. 961; }\end{array}$ \\
\hline Selected values_ & -122 & 48 & .531 & 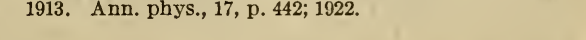 \\
\hline
\end{tabular}

$$
1 \text { From equation }\left(\frac{d P}{d T}\right)_{\nabla}=\left(\frac{d P}{d T}\right)_{\text {coex. }} \quad \text { From rectilinear diameter. }
$$

14 Ter Gazarian, J. chim. phys., 4, p. 140; 1906. 
The argon used by Olszewski was not sufficiently pure to justify a serious consideration of his work in comparison with later observations. Ramsay and Travers employed a rather crude cryostat and obtained their critical pressure by extrapolating vapor pressure measurements, using the rule of Ramsay and Young. ${ }^{15}$

Crommelin extracted argon from the air by absorbing the oxygen and nitrogen with a mixture of calcium carbide and calcium chloride (method of Fischer and Ringe ${ }^{16}$ ). It was then purified by passing over the mixture of quicklime, magnesium, and sodium recommended by Hempel. ${ }^{17}$ The temperatures were measured by means of a platinum resistance thermometer which had been compared with a hydrogen thermometer. Crommelin did not make an exact determination of the critical constants because he suspected that his argon probably contained traces of nitrogen. In addition, his cryostat did not maintain sufficiently constant temperatures.

The more accurate value for the critical density is considered by Crommelin to be that calculated from the rectilinear diameter. Inasmuch as the calculated values of the mean densities differ from the observed data by amounts ranging from +0.00183 to -0.00382 , the use of figures beyond the third decimal does not appear justifiable.

\section{NORMAL BUTANE AND ISOBUTANE}

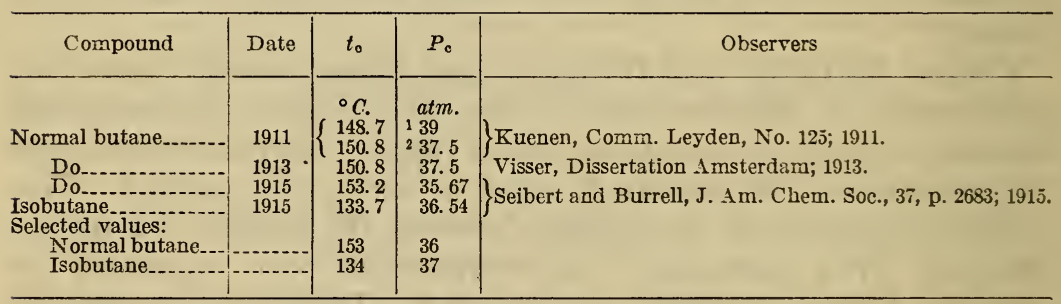

1 Prepared by method of Lebeau, Bull. acad. roy. Belg., p. 300; 1908.

2 Prepared by method of Grignard, Ouedinofi, Bull. soc. chim. Belg., June 23, 1909.

Kuenen's results for normal butane prepared by the two methods are somewhat discordant and he did not feel satisfied with the purity of his samples.

Visser obtained normal butane by employing the Grignard reaction wherein a solution of butyl iodide in ether is added to magnesium and the resulting solution treated with water to liberate the butane. The butane was condensed and subjected to one fractional distillation. The results of the vapor pressure measurements led Visser to believe that the sample contained traces of a substance having a lower boiling point. This substance was thought to be ethane. The presence of this impurity would probably lower the observed critical

15 Ramsay and Young, Phil. Mag. (5), 20, p. 515; 1885;21, p. 33; 22, p. $37 ; 1886$.

${ }^{16}$ Fischer and Ringe, Ber., 41, p. 2017; 1903.

17 Hempel, Gasanalytische Methoden, 3d ed., p. 150. 
pressure, and hence Visser's result would be lower than the true value. He does not describe his method of determining the critical constants.

The isobutane used by Seibert and Burrell was prepared electrolytically by the action of a zine copper couple upon isobutyl iodide and collected over potassium hydroxide. It was then solidified by liquid air, and all remaining gases were removed by evacuating. The gas was fractionally distilled ten times to remove any normal butane. It was later fractionally distilled several times at $-98^{\circ} \mathrm{C}$. Normal butane was prepared from normal butyl iodide and a zinc copper couple, collected over potassium hydroxide and purified by fractional distillation. Each of these gases could be liquefied completely at constant temperature without an appreciable increase of pressure. Several other tests indicated that they were of high purity. The critical temperature was taken as that at which no meniscus was visible when the volume was constant but just appeared when the volume was slightly increased. Duplicate experiments never differed by more than $0.1^{\circ}$. The pressures were measured by a calibrated air manometer.

Inasmuch as both Kuenen's and Visser's results are questionable, preference is given to the values obtained by Seibert and Burrell. Additional determinations are needed to establish the figure beyond the decimal point.

\section{CARBON DIOXIDE}

\begin{tabular}{|c|c|c|c|c|}
\hline Date & $t_{0}$ & $P_{\mathrm{o}}$ & $d_{\mathrm{c}}$ & Observers \\
\hline 1869. & $\begin{array}{l}{ }^{\circ} \mathrm{C} . \\
31.1\end{array}$ & $\begin{array}{l}\text { atm. } \\
\text { 73. } 0\end{array}$ & $g / c c$ & \multirow{12}{*}{$\begin{array}{l}\text { Andrews, Trans. Roy. Soc. London (A), 159, (II), p. 575; } \\
\text { 1869. } \\
\text { Andrews, Trans. Roy. Soc. London (A), 166, (II), p. 421; } \\
\text { 1876. } \\
\text { Hautefeuille and Cailletet, Compt. rcnd., 92, p. 840; } 1881 . \\
\text { Sarrau, Compt. rend., 94, p. 718; 1882. } \\
\text { Dewar, Phil. Mag., 18, p. 210; 1884. } \\
\text { Cailletet and Mathias, Compt. rend., 102, p. 1202; } 1886 . \\
\text { Amagat, Compt. rend., 114, p. 1093; 1892. } \\
\text { Chappuis, Compt. rend., 118, p. 976; 1894. } \\
\text { Villard, J. phys., 3, p. 448; 1894. } \\
\text { Verschafielt, Zitt. Versl., 1896. } \\
\text { Von Wesendonk, Verh. der Deut. Phys. Ges., 5, p. 238; } 1903 . \\
\text { Keesom, Comm. Leyden No. 88; 1903. } \\
\text { Brinkmann, Dissertation Amsterdam; 1904. } \\
\text { Onnes and Fabius, Comm. Leyden No. 98; 1906. } \\
\text { Dorsman, Dissertation Amsterdam; 1908. } \\
\text { Cardoso and Bell, J. chim. phys., 10, p. 500; 1912. } \\
\text { Keyes and Kennedy, Am. Soc. Ref. Eng., 3, No. 4, p. 32; } \\
\text { 1917. } \\
\text { Van Dusen and Meyers, forthcoming publication, Bureau } \\
\text { of Standards. }\end{array}$} \\
\hline 1876 & 30.92 & 77.0 & 0.30 & \\
\hline $\begin{array}{l}1881 \ldots \\
1882- \\
1884 \\
1886\end{array}$ & $\begin{array}{l}* 31.0 \\
(32.0) \\
* 31.9\end{array}$ & $\begin{array}{l}(77.0) \\
* 77.0\end{array}$ & $\begin{array}{l}(.4395) \\
(.65) \\
46\end{array}$ & \\
\hline $\begin{array}{l}1886- \\
1892- \\
1 S 94\end{array}$ & $\begin{array}{l}31.35 \\
* 31.4\end{array}$ & & $\begin{array}{l}.46 \\
.464\end{array}$ & \\
\hline $1894-$ & $* 31.7$ & $\cdots$ & & \\
\hline 1903 & $\begin{array}{l}01.0 \\
30.95\end{array}$ & & & \\
\hline $1903-$ & $\begin{array}{l}30.98 \\
31.12\end{array}$ & 72.93 & .469 & \\
\hline 1506 _ & 30.985 & & .460 & \\
\hline 1908 & 31.10 & 73. 00 & .459 & \\
\hline $\begin{array}{l}1912=- \\
1917=-\end{array}$ & 31.0 & $72.85 \pm 0.1$ & .4597 & \\
\hline $1926 \ldots$ & 31.10 & 72.95 & & \\
\hline Selected values_ & 31.1 & 73.0 & .460 & \\
\hline
\end{tabular}

The determinations of the critical temperature of carbon dioxide all agree remarkably well with the exception of the value given by Sarrau, which was calculated from temperature-pressure-volume data. Dewar, Chappuis, and Villard merely give the figures attributed to them without stating the sources. Van Dusen and Meyers, 
at the Bureau of Standards, have made measurements of the vapor pressure of liquid carbon dioxide over the entire range on material in which the impurities were less than 1 part in 100,000. Their values for the critical temperature and pressure, which are in good agreement with those of the other recent observers, are probably within a tenth of a unit of the true values.

The value for the critical density obtained by Keyes and Kennedy is almost identical with that of Onnes, which is a correction of Keesom's value. The determinations of the critical temperature and pressure made by Andrews in 1869 are remarkably close to the selected values.

\section{CARBON MONOXIDE}

\begin{tabular}{|c|c|c|c|c|}
\hline Date & $t_{0}$ & $P_{0}$ & $d_{0}$ & Observers \\
\hline 1883 & $\begin{array}{l}{ }^{\circ} C . \\
-141.1 \\
-139.5\end{array}$ & $\begin{array}{l}\text { atm. } \\
\text { 34. 6-35. } \\
* 35.5\end{array}$ & $\begin{array}{l}g / c c \\
(0.328)\end{array}$ & \multirow{2}{*}{$\begin{array}{l}\text { Wroblewski, Wied. Ann. Physik., 25, p. 399; } 1885 . \\
\text { Olszewski, Compt. rend., 99, p. 706; 1884; Wied. Ann. } \\
\text { Physik., 31, pp. 66, 70; 1887. } \\
\text { Natanson, J.phys., 4, p. 219; } 1895 . \\
\text { Cardoso, Arch. sci. phys. nat., 39, p. 400; } 1915 . \text { J. } \\
\text { chim. phys., 13, p. 312; 1915. }\end{array}$} \\
\hline Selected values & $\begin{array}{l}-138.7 \\
-139\end{array}$ & $\begin{array}{l}34.60 \\
35 .\end{array}$ & $\begin{array}{l}.3110 \\
.311\end{array}$ & \\
\hline
\end{tabular}

The only recent determinations of the critical constants of carbon monoxide which have been found are those of Cardoso. He prepared carbon monoxide from formic acid and sulphuric acid and passed the gas through potassium hydroxide and phosphorus pentoxide, testing for purity in the usual way by observing the pressure during condensation.

Because Cardoso at this time did practically all of the work alone, he had some difficulty in keeping the temperature constant while making his observations. His temperature measurements, which were made with a pentane thermometer, are open to question and are probably high, judging from his results on nitrogen and oxygen. For these reasons the critical temperature is selected to the nearest degree, and the value for the critical pressure is taken to the nearest atmosphere.

\section{CHLORINE}

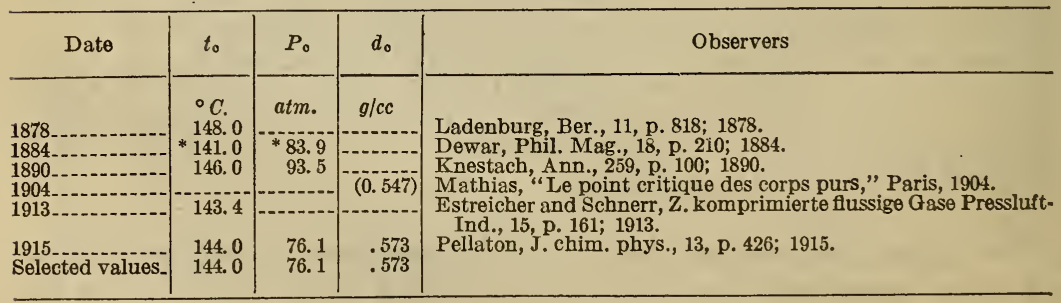

Estreicher and Schnerr and Pellaton have made the only recent determinations of the critical constants of chlorine, and their values for the critical temperature differ from each other by $0.6^{\circ}$. 
Estreicher and Schnerr used the sealed-tube method for their measurements of the critical temperature. The cryostat consisted of a paraffin bath agitated by means of a stream of air and provided with a mercury-in-glass thermometer graduated in half degrees. No further description of their method is given. The mean of 20 measurements of the temperatures of appearance and disappearance of the meniscus using two tubes was $143.4^{\circ}$. These temperatures varied from 142.2 to $144.15^{\circ}$.

Pellaton prepared chlorine by the decomposition of gold chloride. Specially purified gold was heated electrically to $300^{\circ} \mathrm{C}$. in a stream of air to remove moisture and was chlorinated at $200^{\circ} \mathrm{C}$. The laboratory tubes were evacuated to $0.005 \mathrm{~mm}$ of mercury while heated with a Bunsen burner and, after cooling, the chlorine evolved by heating the gold chloride was condensed in them. The tubes were detached with a blowpipe and the critical temperature determined by the sealed-tube method, noting the appearance and disappearance of the meniscus. The mercury-in-glass thermometer was calibrated at $100^{\circ}, 130^{\circ}$, and $154^{\circ} \mathrm{C}$. by means of condensing steam, chlorobenzene and bromobenzene, respectively. The thermostat, which was immersed in a second thermostat maintained the temperatures constant to $0.01^{\circ}$. The difference in temperature between the appearance and disappearance of the meniscus never exceeded $0.2^{\circ}$.

The above work was very carefully carried out, and because of the limited description of the details of Estreicher and Schnerr's work preference is given to the values of Pellaton.

\section{CYANOGEN}

\begin{tabular}{|c|c|c|c|}
\hline Date & $t_{0}$ & $P_{\mathrm{o}}$ & Observers \\
\hline 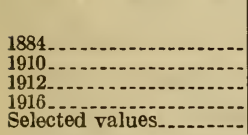 & $\begin{array}{l}{ }^{\circ} \mathrm{C} . \\
{ }^{1} 124.0 \\
128.3 \\
128.3 \\
126.55 \\
128\end{array}$ & $\begin{array}{l}\text { atm. } \\
{ }^{*} 61.7 \\
59.6 \\
59.75 \\
58.2 \\
59\end{array}$ & $\begin{array}{l}\text { Dewar, Phil. Mag., 18, p. 210; } 1884 . \\
\text { Cardoso and Baume, Compt. rend., 151, p. 141; } 1910 . \\
\text { Cardoso and Baume, J. chim. phys., 10, p. 511; } 1912 . \\
\text { Terwen, Z. Physik. Chem., 91, p. 469; 1916. }\end{array}$ \\
\hline
\end{tabular}

Cardoso and Baume prepared cyanogen from mercuric cyanide and mercuric chloride. The gas was dried over phosphorus pentoxide, condensed by means of liquid air and fractionated about nine times. Near the critical temperature cyanogen changes partly into paracyanogen, but these experimenters regard the solubility of paracyanogen in liquid cyanogen as too slight to change the critical constants of the latter.

Terwen prepared his sample by heating a mixture of mercuric cyanide and mercuric chloride to $280^{\circ} \mathrm{C}$. and solidifying the cyanogen after drying with phosphorus pentoxide. The cyanogen thus obtained was fractionally sublimed and the vapor pressures of the 
fractions compared by means of a differential manometer. The purer fractions were put together and repeatedly melted and soliidfied in vacuo to remove any nitrogen. Two fractions of the final sample showed a difference in vapor pressure at $0^{\circ} \mathrm{C}$. of less than 0.03 per cent. The determinations of the critical constants were made in a tube provided with means for measuring and varying the pressure. The pressure was measured by means of a metal manometer which had been calibrated against a hydraulic standard, but Terwen does not make himself clear as to the nature of this standard.

Since there seems to be little choice between the figures obtained by these observers, the recommended values for the critical constants of cyanogen are $128^{\circ}$ and 59 atmospheres. No determinations of the critical density have been found.

\section{ETHANE}

\begin{tabular}{|c|c|c|c|c|}
\hline Date & $t_{0}$ & $P_{0}$ & $d_{0}$ & Observers \\
\hline $\begin{array}{l}1884- \\
1889\end{array}$ & $\begin{array}{c}{ }^{\circ} C . \\
{ }^{*} 35 \\
34\end{array}$ & $\begin{array}{r}\text { atm. } \\
{ }^{*} 45.2 \\
50.2\end{array}$ & $g / c c$ & $\begin{array}{l}\text { Dewar, Phil. Mag. 18, p. 210; } 1884 . \\
\text { Olszewski, Bull. intern. } 1 \text { 'acad. sci. Cracovie, p. 27; } 1889 .\end{array}$ \\
\hline 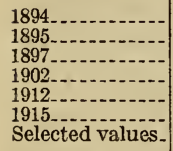 & $\begin{array}{r}32-40 \\
32.2 \\
32.9 \\
31.95 \\
32.1 \\
32.32 \\
32.1\end{array}$ & $\begin{aligned} 50 \\
48.8 \\
48.43 \\
48.85 \\
48.13 \\
48.8\end{aligned}$ & - $21 ?$ & 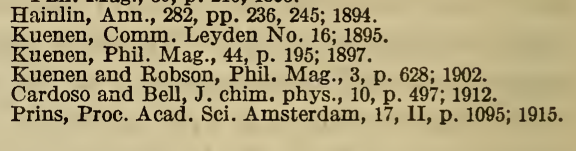 \\
\hline
\end{tabular}

Kuenen, who in 1895 was the first to make reliable measurements of the critical constants of ethane, prepared his sample by the electrolysis of a concentrated solution of sodium acetate. The gas was washed in sulphuric acid and sodium hydroxide solution. It was then passed through fuming sulphuric acid, caustic potash,' and phosphorus pentoxide, after which it was liquefied and distilled. The laboratory tube was provided with an electro-magnetic stirrer to insure equilibrium. That the ethane still contained traces of impurity was indicated by the fact that the pressure increased about 1 per cent when the vapor was condensed at constant temperature. In 1897 he repeated his work, but was again unabie to eliminate all impurities. He and Robson merely state the values given in 1902 .

The ethane used by Cardoso and Bell was prepared by two methods, namely, that of Grignard and that of Frankland and Kolbe, modified by Stahrfoss. In the former method ethyl iodide dissolved in dry ether was slowly added to pure magnesium covered with ether. The ethane was liberated by adding etherized water drop by drop to the mixture. The gas was liquefied, then distilled and passed through alcoholic potassium hydroxide, bromine water, and concentrated sulphuric acid. This cycle was repeated seven times, after which the gas was purified from air by nine fractionations. The second method 
consisted of slowly adding ethyl cyanide to sodium wire, the evolved gas being passed through potassium hydroxide, sulphuric acid, and finally phosphorus pentoxide. The measurements made upon the ethane prepared by the two methods checked very closely.

Prins prepared ethane by electrolyzing a sodium-acetate solution. The gas was purified by bromine water and a strong solution of potassium hydroxide, dried over soda lime and condensed by liquid air. Subsequently it was dried over phosphorus pentoxide and fractionated by the use of liquid air. The details of making the determinations of the critical constants were not stated other than that the Cailletet method was used. The apparatus used in determinations made by this method would consist of a laboratory tube provided with a manometer and a suitable means for varying the volume. The shapes of various isothermals are used to indicate the critical point. As the description of this method is too involved to be included here, the reader is referred to the discussion given by Mathias. ${ }^{18}$

The value selected for the critical temperature is in agreement with the six most recent determinations within $0.2^{\circ}$. In selecting the value for the critical pressure more weight was given to the values obtained by Cardoso and Kuenen and their associates.

\section{ETHYL CHLORIDE}

\begin{tabular}{|c|c|c|c|c|}
\hline Date & $t_{0}$ & $P_{\mathrm{c}}$ & $d_{0}$ & Observers \\
\hline $\begin{array}{l}1859 \\
1884 \\
1886 \\
1995 \\
1904 \\
\text { Selected values. }\end{array}$ & $\begin{array}{l}{ }^{\circ} C . \\
* 184.1 \\
* 182.7 \\
* 189.9 \\
182.5 \\
181.0 \\
181.8 \\
1189.5 \\
187.2 \\
187.2\end{array}$ & $\begin{array}{l}\text { atm. } \\
52.6 \\
54 \\
51.72 \\
52\end{array}$ & \begin{tabular}{|c|}
$g / c c$ \\
\\
$0.328)$ \\
$033 ?$ \\
0
\end{tabular} & $\begin{array}{l}\text { Drion, Ann. chim. phys., 56, p. 221; } 1859 . \\
\text { Sajotschewsky, Kiewer Univers. Unters., } 1878 . \text { Beibl. } \\
\text { Ann. Physik., 3, p. 741; 1879. } \\
\text { Djatschewsky, J. Russ. Phys. Chem. Soc., 16, p. 304; } \\
\text { 1884. Beibl. Ann. Physik., 8, p. 808; 1884. } \\
\text { Vincent and Chappuis, J. phys., 5, p. 58; 1886. } \\
\text { Pictet, Compt. rend., 120, p. 43; 1895. } \\
\text { Pictet and Altschul, Z. physik Chem., 16, p. 26; } 1895 . \\
\text { Eversheim, Ann. Physik., 8, p. 564; 1902. } \\
\text { Mathias, "Le point critique des corps purs," Paris; } 1904 . \\
\text { Berthoud, J.chim. phys., 15, p. 3; 1917. }\end{array}$ \\
\hline
\end{tabular}

1 Corrected for emergent stem.

Berthoud has made the only reliable determinations of the critical constants of ethyl chloride. Neither Vincent and Chappuis, Pictet and Altschul, nor Eversheim state how they prepared their sample, and the earlier observers merely give results.

The sample used by Berthoud was obtained from Kahlbaum and was purified by fractional distillation. The portion boiling between 12.5 and $12.6^{\circ} \mathrm{C}$. at $725 \mathrm{~mm}$ of mercury was utilized for the measurements. The appearance and disappearance of the meniscus were the criteria employed in the determination of the critical temperature. The critical pressure was measured by means of a thermometer placed inside of a slightly larger tube which contained the ethyl

18 Mathias, "Le point critique des corps purs," Paris; 1904. $6848^{\circ}-26-3$ 
chloride. The lower end of the tube containing the bulb of the thermometer was placed in ice, and this was kept at constant temperature while the upper end was surrounded by a paraffin bath, the temperature of which could be regulated. This bath was contained in an inverted flask the bottom of which had been removed, and which was supported on the tube by means of a stopper. The pressure on the bulb of the thermometer was indicated by the position of the mercury in the capillary. The pressure of the saturated vapor of carbon dioxide was employed in the calibration of the manometer, using the data of Amagat for the vapor tension of this substance. Later work indicates that Amagat's values are probably 0.2 or 0.3 atmosphere low at pressures of about 55 atmospheres, and if allowance is made for this difference Berthoud's value for the critical pressure would be about 52 atmospheres.

The value for the critical density given by Mathias was calculated from considerations involving the law of corresponding states and is not reliable, although it yields a reasonable value for the expression $\frac{R T_{c} d_{c}}{M P_{c}}$

\section{ETHYLENE}

\begin{tabular}{|c|c|c|c|c|}
\hline Date & ${ }^{\circ} \mathrm{C}$ & $P_{0}$ & $d_{0}$ & Observers \\
\hline $\begin{array}{l}1880 \\
1882 \\
1882 \\
1884 \\
1895 \\
1897 \\
1912 \\
1921 \\
\text { Selected values }\end{array}$ & $\begin{array}{c}t_{0} \\
9.2 \\
13 \\
(1.5) \\
-10.1\end{array}$ & \begin{tabular}{c|} 
atm. \\
58 \\
\hdashline$(43.5$ \\
51.0 \\
51.7 \\
50 \\
50.65 \\
\hdashline 50.9
\end{tabular} & $\begin{array}{c}g / c c \\
0.36 \\
(.187) \\
.22 \\
.22 \\
.22\end{array}$ & 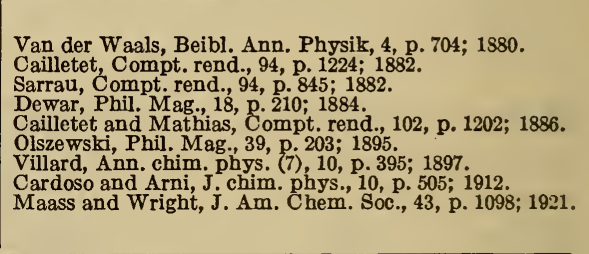 \\
\hline
\end{tabular}

The only recent determinations of the critical constants of ethylene are those of Cardoso and Arni and of Maass and Wright.

Cardoso and Arni prepared ethylene from sulphuric acid and ethyl alcohol, passed the gas through two columns of solid potassium hydroxide, two bulbs of concentrated sulphuric acid, and dried it over phosphorus pentoxide, after which it was fractionated 10 times.

The ethylene used by Maass and Wright was prepared by the dehydrating action of aluminum oxide upon purified ethyl alcohol at a temperature of $350^{\circ} \mathrm{C}$. The sample was then purified by several distillations, a final purification being obtained by distilling five times in a vacuum, the middle portions being retained in each instance. The temperatures were measured by a platinum resistance thermometer for which an accuracy of $0.2^{\circ}$ was claimed. These authors do not state how the critical temperature was obtained. 
The value selected for the critical temperature is the mean of these two determinations. The correction applied to the value for the critical pressure is 1.2 atmospheres per degree.

The determination of the critical density by Cailletet and Mathias, while quite old, yields a reasonable value for the ratio $\frac{R T_{c} d_{c}}{M P_{c}}$.

14. HELIUM

\begin{tabular}{|c|c|c|c|c|}
\hline Date & $t_{0}$ & $P_{0}$ & $d_{0}$ & Observers \\
\hline 1908 & $\begin{aligned} &{ }^{\circ} C . \\
&-268 \\
&-268 \\
&-267.6 \\
&-267.85 \\
&-267.90 \\
&-267.9\end{aligned}$ & $\begin{array}{r}\text { atm. } \\
2.3 \\
2.75 \\
2.26 \\
2.26\end{array}$ & $\begin{array}{c}g / c c \\
0.065 \\
.066 \\
0.06930 \\
.0693\end{array}$ & $\begin{array}{l}\text { Onnes, Comm. Leyden No. 108; } 1908 . \\
\text { Onnes, Comm. Leyden No. } 112 ; 1909 . \\
\text { Onnes, Comm. Leyden No. } 119 ; 1911 . \\
\text { Onnes, Comm. Leyden No. 124b; } 1911 \text {. Proc. Acad. } \\
\text { Sci. Amsterdam, 14, p. 678; } 1912 \text {. } \\
\text { Onnes and Weber. Comm. Leyden No. 147b; } 1915 . \\
\text { Proc. Acad. Sci. Amsterdam, 18, p. 506; } 1916 . \\
\text { Mathias, Crommelin, Onnes, and Swallow, Comm. } \\
\text { Leyden No. 172b; } 1925 .\end{array}$ \\
\hline
\end{tabular}

An accuracy of $0.1^{\circ}$ is claimed for the value which Onnes gives as the critical temperature of helium. The critical pressure given is a lower limit; the true value is believed by Onnes to be slightly higher. The critical density was obtained from measurements of the densities of the saturated liquid and vapor phases by extrapolating the resulting rectilinear diameter to the critical temperature.

\section{HYDROGEN}

\begin{tabular}{|c|c|c|c|c|}
\hline Date & $t_{0}$ & $P_{c}$ & $d_{e}$ & Observers \\
\hline 1882 & $\begin{array}{c}{ }^{\circ} C . \\
(-174.2) \\
(-240.4)\end{array}$ & $\begin{array}{l}\text { atm. } \\
(98.9) \\
(13.3)\end{array}$ & $\begin{array}{c}g / c c \\
(0.050)\end{array}$ & $\begin{array}{l}\text { Sarrau, Compt. rend., 94, p. 845; } 1882 . \\
\text { Wroblewski, Sitz. Akad. Wiss. Wien., } 91,1885 \text {. Sitz. }\end{array}$ \\
\hline 1895. & -234.5 & 20.0 & & Olszewski, Phil. Mag., 39, p. 202; 1895. \\
\hline $1895=$ & -221 & -19.4 & $(.043)$ & $\begin{array}{l}\text { Natanson, J. phys., 4, p. } 219 ; 1895 . \\
\text { Dewar, Proc. Roy. Soc. (London), 64, p. 227; } 1899 .\end{array}$ \\
\hline $1901 \ldots$ & $\begin{array}{l}-241 \\
-243\end{array}$ & & & Dewar, Chem. News, 84, p. 293; 1901. \\
\hline 1902 & -241 & 15 & & Dewar, Reported by Clerke, J. phys. (4), 1, p. 116; \\
\hline 1904 & -240.8 & $13.4-15.0$ & .033 & $\begin{array}{l}\text { Dewar, Proc. Roy. Soc. (London), 73, p. 251; } 1904 . \\
\text { Olszewski, Ann. Physik., 17, p. } 986 ; 1905 ; 8 \text {, p. 193; }\end{array}$ \\
\hline 1913 & $\begin{array}{l}-241.15 \\
-239.92\end{array}$ & $\begin{array}{l}11.0 \\
12.80\end{array}$ & .0310 & Bulle, Physik. Z., 14, p. 860; 1913 . \\
\hline 1921. & & & .03102 & $\begin{array}{l}\text { sterdam, 20, p. 178; 1917; Comm. Leyden No. 151c. } \\
\text { Matbias, Crommelin and Onnes, Comm. Leyden }\end{array}$ \\
\hline Selected values. & -239.9 & 12.8 & .0310 & \\
\hline
\end{tabular}

The first experimental measurements of the critical constants of hydrogen were made by Olszewski in 1895. In 1905 he redetermined the constants by a greatly improved method, using liquid hydrogen as the cooling medium. He found that the meniscus appeared at 13.4 atmospheres and disappeared at 15 atmospheres.

The work of Bulle followed in 1913, but according to Onnes it seems unlikely that the temperatures within the apparatus were uniform. 
Onnes ${ }^{19}$ and his coworkers developed a special cryostat with which they were able to maintain very constant temperatures. Because of this improved apparatus their results are probably the most accurate thus far obtained.

They purified their hydrogen by fractional distillation and made careful determinations of a number of isothermals, the temperatures being measured by means of a helium thermometer. By connecting the points on these isothermals corresponding to the beginning and completion of liquefaction, a parabola was obtained and the pressure corresponding to the vertex of this parabola was taken as the critical pressure. The corresponding temperature was found by extrapolation from the vapor pressure measurements immediately below the critical temperatures. The vapor pressure lines of these isothermals were closely parallel to the volume axis, which shows that the purity of the sample was very high. The critical density was calculated by means of the law of Callietet and Mathias, using the density data previously published. ${ }^{20}$ This method is discussed in the introduction.

It is interesting to note how remarkably close Wroblewski's calculated values for the critical temperature and pressure are to the recent experimental ones.

\section{HYDROGEN BROMIDE}

\begin{tabular}{|c|c|c|c|}
\hline Date & $t_{0}$ & $P_{\text {o }}$ & Observers \\
\hline -.-.-.-.- & $\begin{array}{l}{ }^{\circ} \mathrm{C} . \\
{ }_{90.8}\end{array}$ & atm. & Estreicher, Z. physik. Chem., 20, p. $605 ; 1896$. \\
\hline $1913 \ldots$ & 90 & 84.44 & $\begin{array}{l}\text { Pressluft-Ind., 15, p. 161; 1913. } \\
\text { Drozdowski and Pietrzak, Anz. Akad. Wiss. Krakau, }\end{array}$ \\
\hline $\begin{array}{l}\text { 1919 } \\
\text { Selected values...-..... }\end{array}$ & $\begin{array}{l}89.80 \\
90\end{array}$ & $\begin{array}{l}(84) \\
84\end{array}$ & Moles, J. chim. phys., 17, p. 421; 1919. \\
\hline
\end{tabular}

Estreicher prepared hydrogen bromide by the action of bromine on red phosphorus in the presence of water and removed the excess bromine vapor by passing the gas through a tube containing a suspension of red phosphorus in water. The hydrogen bromide was liquefied and distilled into tubes and sealed. The critical temperature was determined by noting the temperatures at the time of the appearance and disappearance of the meniscus. The mean of 17 observations of the appearance of the meniscus was $90.4^{\circ}$, while that of 23 observations of the disappearance was $91.3^{\circ}$. The individual values are not given.

Estreicher and Schnerr say very little regarding either their methods of purification or their method of measurement of the critical temperature (see discussion of chlorine). The mean of 20

10 Onnes, Comm. Leyden No. 154c., Proc. Acad Sci. Amsterdam, 23, II, p. 1185; 1922.

${ }^{20}$ Cailletet and Mathias, Comm. Leyden Nos. 127c and 137. 
observations of the temperatures of the appearance and disappearance of the meniscus is $91.07^{\circ}$. These temperatures varied from 90.3 to $91.74^{\circ}$.

Drozdowski and Pietrzak obtained hydrogen bromide directly from hydrogen and bromine by passing these gases over heated platinized asbestos. The hydrogen bromide was solidified by cooling with liquid air and the excess hydrogen pumped off, final traces being removed by opening a stopcock leading to a bulb immersed in liquid air and containing charcoal.

The hydrogen bromide was submitted to fractional distillation and then distilled into the sample tube. The tube projected through a cork in the bottom of a glass vessel up into a bath provided with a thermometer and stirrer and heated with a ring burner. A glassspiral manometer with an attached mirror was sealed to the lower end of the tube. This manometer was calibrated against a pressure gauge of the aneroid manometer type.

The hydrogen was obtained from a Kipp generator without purification, and the hydrogen bromide was fractionally distilled only once. The authors admit that the discrepancies between check tests of the vapor pressures above four atmospheres, which in some cases differ by over 10 per cent, are due to impurities in the samples. Their measurements of the vapor pressures extend only up to $87^{\circ}$, and no statement is made regarding their observations at the critical point.

From his researches on hydrogen bromide Moles ${ }^{21}$ found that impurities were present when this gas was prepared according to the method used by Estreicher in 1896. Moles prepared hydrogen bromide from metaphosphoric acid and potassium bromide. The gas was liquefied and distilled into sample tubes. A tube containing a suitable amount of hydrogen bromide for observing the critical phenomena was supported in a double-walled ressel containing: paraffin and provided with two stirrers. A thermometer, graduated in tenths of a degree, was supported beside the tube. The temperatures were noted during the occurrence of the following phenomenathe appearance and disappearance of the meniscus and the appearance of the critical opalescence. In the five sets of observations made the temperatures varied from 89.60 to $89.80^{\circ}$, with the critical opalescence appearing at the latter temperature. The critical pressure was calculated from five empirical formulas, the extreme values being 71 and 99 atmospheres.

As stated in the introduction, this method of determining the critical temperature is not always reliable. The value chosen is the whole number corresponding to the mean of the last three determinations. The critical pressure is taken to be 84 atmospheres. 
17. HYDROGEN CHLORIDE

\begin{tabular}{|c|c|c|c|c|}
\hline Date & $t_{0}$ & $P_{0}$ & $d_{0}$ & Observers \\
\hline $\begin{array}{l}1879 \\
1884 \\
1886 \\
1894 \\
1904-\ldots-\end{array}$ & $\begin{array}{l}{ }^{\circ} C . \\
51.25 \\
* 52.3 \\
51.5 \\
52.0 \\
\end{array}$ & $\begin{array}{c}\text { atm. } \\
86 \\
\quad 86 \\
96 \\
83\end{array}$ & $\begin{array}{c}g / c c \\
(0.61) \\
(.462)\end{array}$ & $\begin{array}{l}\text { Ansdell, Chem. News, 41, p. } 75 ; 1880 . \\
\text { Dewar, Phil. Mag., 18, p. 210; } 1884 . \\
\text { Vincent and Chappuis, J. phys., 5, p. 58; } 1886 \text {. } \\
\text { Leduc and Sacerdote, Compt. rend., 125, p. 397; 1897. } \\
\text { Mathias (calculated from experiments by Ansdell), }\end{array}$ \\
\hline $1906-1908$ & $\begin{array}{l}51.8 \\
51.0 \\
51.4 \\
51.4\end{array}$ & $\begin{array}{l}83.6 \\
81.5 \\
81.55\end{array}$ & .423 & $\begin{array}{l}\text { Briner, J. chim. phys., 4, p. 476; } 1906 . \\
\text { Dorsman, Dissertation Amsterdam, } 1908 . \\
\text { Cardoso and Germann, J. chim. phys., 10, p. } 517 ; 1912 . \\
\text { Estreicher and Schnerr, Z komprimierte flüssige Gase } \\
\text { Pressluft. Ind. }\end{array}$ \\
\hline $1913 \ldots \ldots$ & 51.1 & 80.49 & & Drozdowski and Pietrzak, Anz. Akad. Wiss. Krakau, \\
\hline Selected values. & 51.4 & 81.6 & .42 & \\
\hline
\end{tabular}

The various observations of the critical temperature of hydrogen chloride are in good agreement.

The only criterion of the purity of Leduc and Sacerdote's sample, which was prepared from sulphuric acid and sodium chloride, was that of complete absorption by water.

The hydrogen chloride used by Briner was purified by fractional distillation. He does not describe his method of observation.

Dorsman condensed the hydrochloric acid (prepared from sodium chloride and sulphuric acid which had been boiled to expell air) by means of liquid air. The sample tube was evacuated and then washed out several times with the hydrochloric acid gas. He used the Cailletet method in making his determinations (see discussion of ethane).

Drozdowski and Pietrzak prepared hydrogen chloride by the action of sulphuric acid on sodium chloride and submitted the sample to fractional distillation. The apparatus used in making the measurements of the vapor pressure is described in the discussion of hydrogen bromide. No mention is made, however, of the conditions defining the critical point.

Estreicher and Schnerr obtained their value as a mean of 15 measurements of the temperatures of the appearance and disappearance of the meniscus, using two sealed tubes. These temperatures varied from 50.8 to $51.9^{\circ}$. As mentioned in the discussion of chlorine, these observers do not discuss their methods of purification.

Cardoso and Germann used concentrated sulphuric acid and pure precipitated sodium chloride and passed the evolved gas through five bottles of concentrated sulphuric acid and a tube of phosphorus pentoxide. The hydrogen chloride was then distilled 10 times and passed over phosphorus pentoxide after each of the first six fractionations.

The elaborate precautions taken by Cardoso and Germann in purifying their samples and in making their measurements justifies the selection of their results as the most reliable. 
Dorsman's value for the critical density was obtained by calculating from the rectilinear diameter and yields a reasonable figure for the ratio $\frac{R T_{c} d_{c}}{M P_{c}}$. His direct observation $(0.411)$ is less reliable, and this discrepancy, together with the low critical temperature, renders the third decimal doubtful.

\section{HYDROGEN IODIDE}

\begin{tabular}{|c|c|c|c|}
\hline Date & $t_{0}$ & $P_{0}$ & Observers \\
\hline $\begin{array}{l}1896 \\
1913 \\
\text { Selected values. }\end{array}$ & $\begin{array}{l}{ }^{\circ} C . \\
150.7 \\
150.8 \\
150 \\
151\end{array}$ & $\begin{array}{c}\text { atm } \\
80.8 \\
82\end{array}$ & $\begin{array}{l}\text { Estreicher, Z. physik. Chem., 20, p. 605; } 1896 . \\
\text { Estreicher and Schnerr, Z. komprimierte flüssige Gase } \\
\text { Pressluft-Ind., 15, p. 161; 1913. } \\
\text { Drozdowski and Pietrzak, Anz. Akad. Wiss. Krakau, 4, } \\
\text { A, p. 219; 1913. }\end{array}$ \\
\hline
\end{tabular}

Estreicher's first determination of the critical temperature of hydrogen iodide was made with a sample prepared by the action of red phosphorus upon a mixture of pulverized iodine and water. After the removal of most of the iodine vapor with water the gas was dried with phosphorus pentoxide and solidified by means of a mixture of solid carbon dioxide and ether. The remaining iodine was removed by distillation. According to these determinations, which were made in a sealed tube, the meniscus disappeared at $150.7^{\circ}$ and appeared again at $150.4^{\circ}$. This value was later checked to $0.1^{\circ}$ by Estreicher and Schnerr.

Drozdowski and Pietrzak prepared hydrogen iodide by the method which they used to obtain hydrogen bromide, the bromine being replaced by iodine. Their vapor pressure measurements extend only to $147^{\circ}$, and no description of the conditions at the critical point is given.

There is little choice between the results obtained for this gas. In selecting a value for the critical temperature no decimal place is given, and the agreement between the first two observations would favor the adoption of $151^{\circ}$. The value for the critical pressure obtained by Drozdowski and Pietrzak is corrected to correspond to this temperature.

19. HYDROGEN SULPHIDE

\begin{tabular}{|c|c|c|c|}
\hline Date & $t_{0}$ & $P_{\mathrm{o}}$ & Observers \\
\hline 884 & $\begin{array}{l}{ }^{\circ} C . \\
{ }^{*} 100.2 \\
100.0\end{array}$ & $\begin{array}{l}\underset{* 92}{a t m .} \\
88.7\end{array}$ & \multirow{3}{*}{$\begin{array}{l}\text { Dewar, Phil. Mag., 18, p. 210; 1884. } \\
\text { Olszewski, Beibl. Ann. Physik., 14, p. 896; 1890. Bull. } \\
\text { Akad. Krakau, 18, p. 57; 1890. 18. } \\
\text { Leduc and Sacerdote, Compt. rend., 125, p. 397; } 1897 . \\
\text { Scheffer, Z. physik. Chem., 71, p. 695; 1910. } \\
\text { Estreicher and Schnerr, Z. Komprimierte flüssige Gase } \\
\text { Pressluft-Ind., 15, p. 161; 1913. } \\
\text { Cardoso and Arni, J. chim. phys., 10, p. 504; 1912. } \\
\text { Cardoso, Gazz. chim. Ital. 51, I, p. 153; 1921. }\end{array}$} \\
\hline 1897 & $\begin{array}{c}100.0 \\
99.6 \\
100.43\end{array}$ & $\begin{array}{l}90 \\
88.3\end{array}$ & \\
\hline $\begin{array}{l}1912 \\
\text { Selected values..... }\end{array}$ & $\begin{array}{r}100.4 \pm 0.1 \\
100.4 \\
100.4\end{array}$ & $\begin{array}{c}89.05 \pm 0.1 \\
88.90 \\
88.9\end{array}$ & \\
\hline
\end{tabular}


Scheffer prepared hydrogen sulphide by the action of dilute sulphuric acid on a sodium hydrosulphide solution containing barium sulphide and purified the gas by fractionation. His determinations were apparently not carried out with as many precautions as those of the later observers.

Such details of the work of Estreicher and Schnerr as are given are mentioned in the discussion of chlorine. Twenty measurements of the temperatures of the appearance and disappearance of the meniscus varied from 100.03 to $100.84^{\circ}$.

Cardoso and Arni prepared their samples from hydrochloric acid and pure precipitated ferrous sulphide. The hydrogen sulphide was passed through a suspension of ferrous sulphide in water and thence over calcium chloride and phosphorus pentoxide, after which it was fractionally distilled 14 times. They found that all the mercury, as well as the gas, had to be very carefully dried, otherwise a slight decomposition would take place, which proceeded apparently until a definite small pressure of hydrogen was produced.

Cardoso in 1921 took additional precautions to eliminate traces of hydrogen and of substances of higher boiling point which he took to be polysulphides of hydrogen. The hydrogen sulphide was absorbed by a suspension of magnesium hydroxide in water which was later heated and the evolved hydrogen sulphide dried by passing through a condenser and a long tube containing phosphorous pentoxide. The presence of the substance of higher boiling point was indicated by the small droplets adhering to the walls of tubes after pouring off the liquid hydrogen sulphide. The sample was distilled into a tube consisting of two bulbs with a constriction between. The lower bulb containing the liquid hydrogen sulphide was cooled to $-80^{\circ} \mathrm{C}$. for an hour and a half and then inverted, placed in the cooling medium again, and the upper bulb containing the adhering droplets sealed off. The hydrogen sulphide was then subjected to fractional distillation.

The precautions taken by Cardoso in purifying the sample justify the acceptance of his values for the critical temperature and pressure. No determinations of the critical density have been found.

20. KRYPTON

\begin{tabular}{|c|c|c|c|c|}
\hline Date & $t_{0}$ & $P_{\mathrm{o}}$ & $d_{\mathrm{c}}$ & Observers \\
\hline 1901 & $\begin{array}{l}{ }^{\circ} C . \\
-62.5\end{array}$ & $\underset{54.3}{a t m}$ & $g / c c$ & \multirow{3}{*}{$\begin{array}{l}\text { Ramsay and Travers, Trans. Roy. Soc. (London), 197, } \\
\text { p. } 87 ; 1901 . \\
\text { Rudorf, Ann. Physik, (4), 29, p. 751; 1909; Zeit. Electro- } \\
\text { Chem., 15, p. 746; 1909. }\end{array}$} \\
\hline $1901 \ldots$ & & & $(0.775)$ & \\
\hline Selected values_- & $-63 ?$ & $54 ?$ & $78 ?$ & \\
\hline
\end{tabular}

Ramsay and Travers separated krypton from oxygen, nitrogen, and xenon by repeated fractionations, but because of the small quantities of gas with which they had to deal it is doubtful whether their samples were very pure. 
The value for the critical density was calculated by Rudorf from the formula given by Mathias. ${ }^{22}$ The value which Rudorf calculates for argon is 0.488 , while that observed is 0.531 , so that the second significant figure is unreliable.

\section{METHANE}

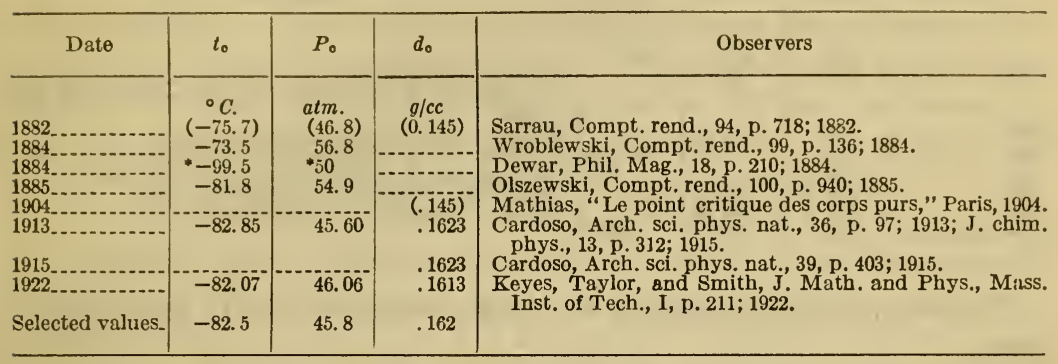

Cardoso prepared methane by the action of water on methyl magnesium iodide. The methane was stored over water for two or three days and then bubbled through potassium hydroxide solution and through concentrated sulphuric acid, after which it was dried by means of phosphorus pentoxide. The methane was then purified by 10 fractional distillations in a vacuum at the temperature of liquid air.

Keyes, Taylor, and Smith used methane prepared by heating a mixture of dry sodium acetate and soda lime. Any acetone formed was absorbed by 20 per cent fuming sulphuric acid, the sulphur trioxide fumes being removed by 98 per cent sulphuric acid. The gas was passed through a caustic soda solution and then over solid caustic and phosphorus pentoxide. Further purification was obtained by fractional distillation. The impurities were not in excess of 1 part in 500. The critical constants, it is stated, were directly observed, but the method is not described. The sample was not stirred during the determination.

Cardoso's values for the vapor pressure were found to be uniformly higher than those of Keyes and his coworkers by an amount corresponding to a temperature difference of $0.56^{\circ}$, and these authors, therefore, assume that Cardoso's temperature measurements are low by this amount. On the other hand, from a footnote, ${ }^{23}$ it is apparent that Cardoso's fixed point-the freezing point of toluene-is too high. This contradiction taken together with the statement on a preceding page that the higher vapor pressures were not very concordant because of lack of sufficient stirring would throw doubt upon validity of the proposed correction.

${ }_{22}$ Mathias, Le point critique des corps purs, p. 164, Paris, 1904.

${ }^{28}$ Keyes, Taylor, and Smith, J. Math. and Phys., Mass. Inst. of Tech. I, p. 226; 1922. 
The critical constants selected are the means of these two recent sets of observations, the correction of 1.4 atmospheres per degree being applied to the values for the critical pressure.

\section{METHYL CHLORIDE}

\begin{tabular}{|c|c|c|c|c|}
\hline Date & $t_{0}$ & $P_{\mathrm{o}}$ & $d_{0}$ & Observers \\
\hline 1886_- & $\begin{array}{l}{ }^{\circ} C . \\
141.5\end{array}$ & $\begin{array}{c}\text { atm. } \\
73\end{array}$ & $g / c c$ & \multirow{5}{*}{$\begin{array}{l}\text { Vincent and Chappuis, Compt. rend., 100, p. 1216; } 1885 \\
\text { J. phys. (2), 5, p. 58; 1886. Compt. rend., 103, p. } 379 \\
\text { 1886. } \\
\text { Kuenen, Arch. Neerland., 26, p. 368; 1893. } \\
\text { Mathias, "Le point critique des corps purs," Paris; } 1904 \\
\text { Centnerswer, Z. physik. Chem., 49, p. 203; 1904. } \\
\text { Brinkmann, Dissertations Amsterdam, 1904. } \\
\text { Baume, J. chim. phys., 6, p. 1; 1908. }\end{array}$} \\
\hline 1893.- & 143.0 & 65.0 & \multirow{2}{*}{$\begin{array}{c}(0.354) \\
\quad .370\end{array}$} & \\
\hline & 143.0 & & & \\
\hline & 143. 12 & 65.93 & & \\
\hline Selected values. & $\begin{array}{l}143.2 \\
143.1\end{array}$ & $\begin{array}{l}65.85 \\
65.8\end{array}$ & . & \\
\hline
\end{tabular}

The recent determinations on methyl chloride are in good agreement.

Centnerszwer purified his sample by passing it over soda lime, calcium chloride, and sulphuric acid, after which it was distilled into the tubes. No variation in pressure was observed when the gas was condensed at constant temperature. He did not stir the gas while making the determinations.

Baume passed the methyl chloride through sulphuric acid and fractionated it five or six times. The results of these observers are averaged with those of Brinkmann.

The values which Centnerszwer obtained for the density by the method of Cailletet and Mathias varied, within $0.01^{\circ}$ of the critical temperature, from 0.3397 to 0.3790 . When it is considered that his figure for the critical temperature may be in error by $0.2^{\circ}$, it is unlikely that the value for the critical density is accurate to even the second significant figure.

\section{NEON}

\begin{tabular}{|c|c|c|c|c|}
\hline Date & $t_{0}$ & $P_{0}$ & $d_{\mathrm{c}}$ & Observers \\
\hline & & ${ }_{29}^{a t m}$. & $g / c c$ & \multirow{6}{*}{$\begin{array}{l}\text { Onnes, Comm. Leyden No. 112; } 1909 . \\
\text { Rankin, Pbil. Mag., 21, p. 45; 1911. } \\
\text { Onnes, Crommelin and Cath, Comm. Leyden No 151b; } \\
\text { 1917. Proc. Acad. Si. Amsterdam, 19, p. 1058; 1917. } \\
\text { Crommelin, Comm. Leyden No. 162c; 1923. Rec. trav. } \\
\text { chim., 42, p. 814; 1923. } \\
\text { Mathias, Crommelin and Onnes, Comm. Leyden No. } \\
\text { 162b; 1923. Ann. phys., 19, p. 231; 1923. }\end{array}$} \\
\hline $1911 \ldots$ & $\left.\begin{array}{c}(-210.4 \\
0 r-212\end{array}\right)$ & & & \\
\hline $917 .$. & -228.36 & 26.86 & & \\
\hline 1923... & -228.72 & & & \\
\hline $923 \ldots$ & & - & 0.4835 & \\
\hline Selected values & -228.7 & 25.9 & .484 & \\
\hline
\end{tabular}

Onnes, Crommelin, and Cath made the first published determination of the critical constants of neon. The impure gas which they had at their disposal was freed from hydrogen by explosion with oxygen. The material was then repeatedly frozen and distilled over charcoal cooled in liquid air. Traces of impurities still remained, however, as indicated by the increase of pressure (about 0.8 per 
cent) when the gas was liquefied at constant temperature; and because of these impurities the values for the critical temperature and critical pressure are believed by Onnes and his coworkers to differ from the true values by a few tenths of a unit. The temperatures were measured with a helium thermometer. Vapor-pressure measurements were made, and the apparatus was so arranged that the quantities of gas which were liquefied at a given temperature between the beginning and the end of condensation could be measured. Using the values obtained in this manner at different temperatures in the neighborhood of the critical temperature, the critical constants were calculated by extrapolation over a small range.

The value for the critical temperature was later determined by Crommelin, who subjected the neon to further purification. In addition to the precautions taken by his predecessors, Crommelin passed the neon through a coil immersed in liquid hydrogen maintained at $-253^{\circ} \mathrm{C}$. The neon was kept at a pressure of about 12 $\mathrm{mm}$ which corresponds to its vapor pressure at this temperature. Whatever oxygen or nitrogen might have remained dissolved in the liquid neon was thus removed. The neon after passing through the coil was solidified and then fractionated. The first portion was rejected because of the possible presence of traces of helium. The correction for the critical pressure is three atmospheres per degree.

The neon purified by Crommelin was used for the determination of the critical density by measuring the densities of the liquid and vapor phases at temperatures just below the critical and establishing the equation for the rectilinear diameter. Inasmuch as the three observations at temperatures nearest the critical give values for the mean density which are higher than the calculated values by the amounts $0.00052,0.00269$, and 0.00078 , it seems probable that the calculated value is slightly low, and that 0.484 is more nearly the true value.

\section{NITRIC OXIDE}

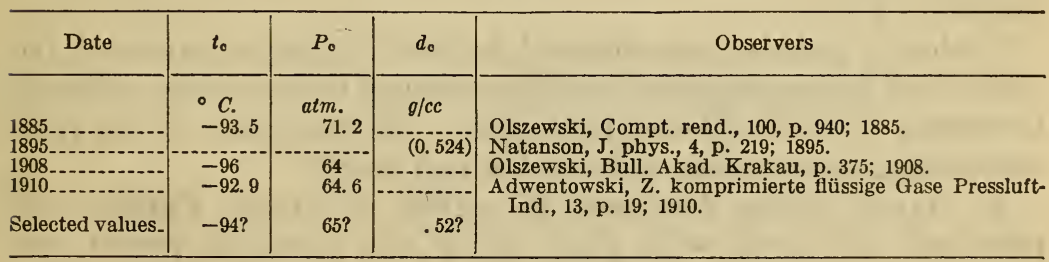

Olszewski, in 1885, did not make observations at the critical point of nitric oxide, for he found the meniscus still visible at $-93.5^{\circ}$ and 71.2 atmospheres, and owing to his fear that the tube might burst he did not raise the temperature further. He later, in 1908, reports a redetermination of the critical constants of this substance but does not give details. 
Adwentowski measured the vapor pressures of nitric oxide at various temperatures up to the critical, using the Cailletet apparatus (see discussion of ethane). He does not give his method of preparation or of purification, but states that his analyses indicated the maximum amount of impurities to be 0.25 per cent.

The value selected for the critical temperature is the whole number nearer the mean of the last two determinations. A correction of 2.2 atmospheres per degree is applied to the corresponding pressures.

The value for the critical density calculated by Natanson is unreliable and gives a rather high value (3.9) for the expression $\frac{R T_{\mathrm{c}} d_{\mathrm{c}}}{M P_{\mathrm{c}}}$.

\section{NITROGEN}

\begin{tabular}{|c|c|c|c|c|}
\hline Date & $t_{\mathrm{c}}$ & $P_{0}$ & $d_{0}$ & Observers \\
\hline 382 & $\stackrel{\circ C .}{(-123.8)}$ & $\begin{array}{l}\text { atm. } \\
(42.1)\end{array}$ & $\begin{array}{l}g / c c \\
(0.2719)\end{array}$ & Sarrau, Compt. rend., 94, p. 718; 1882. \\
\hline & -146 & 39.2 & 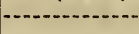 & Olszewski, Compt. rend., 98, p. 913; 1884. \\
\hline 1884- & -140 & & & $\begin{array}{l}\text { Olszewski, Compt. rend., 99, p. }{ }^{133 ;} 1884 . \text { Wied. } \\
\text { Ann. Physik, } 31 \text {, pp. } 66,70 ; 1887 . \text { Phil. Mag., } 39, \\
\text { p. } 210 ; 1895 .\end{array}$ \\
\hline 1884 & $\begin{array}{l}*-146 \\
-146\end{array}$ & $\begin{array}{rl}* & 35 \\
33\end{array}$ & $(.45)$ & $\begin{array}{l}\text { Dewar, Phil. Mag., 18, p. } 210 ; 1884 . \\
\text { Wroblewski, Wien. Ber., } 91, \quad \text { p. } 696 ; 1885 . \quad \text { Wien. }\end{array}$ \\
\hline 1886 & -146.5 & & .44 & $\begin{array}{l}\text { Ber., 92, p. 641; } 1885 . \\
\text { Wroblewski, Compt. rend., 102, p. 1010; } 1886 .\end{array}$ \\
\hline & $1 x u .0$ & & & $\begin{array}{l}\text { Wroblewski, Sitz. Akad. Wiss. Wien., 97, p. } 1378 \text {; } \\
1888 \text {. }\end{array}$ \\
\hline 1904 & & & $(.296-.299)$ & $\begin{array}{l}\text { Mathias, "Le point critique des corps purs," Paris; } \\
\text { 1904. }\end{array}$ \\
\hline 1904.. & -147.13 & 33,49 & .3269 & Dewar, Proc. Roy. Soc. London, 73, p. 251; 1904 \\
\hline $101 \%-$ & -141.10 & 30. 49 & & 145b; 1914. Proc. Akad. Sci. Amsterdam, 17, II, p. \\
\hline 1914 & & & .31096 & $\begin{array}{l}\text { Mathias, Onnes, and Crommelin, Comm. Leyden } \\
\text { No. 145c; 1914. Ann. phys., 17, p. 455; } 1922 \text {. }\end{array}$ \\
\hline Selected values- & $\begin{array}{l}-144.7 \\
-147.1\end{array}$ & $\begin{array}{l}33.65 \\
33.5\end{array}$ & .3110 & Cardoso, J. chim. phys., 13,p. 312; 1915. \\
\hline
\end{tabular}

The nitrogen used by Onnes, Dorsman, and Holst was prepared by boiling a solution of sodium nitrite and sodium sulphate with ammonia. The gas was passed over sulphuric acid to remove the ammonia. During condensation at constant temperature there was no appreciable increase in pressure, so that the gas may be considered as pure.

Cardoso's sample was obtained by heating pure potassium trinitride and passing the gas over pure calcined barium oxide, followed by drying over phosphorus pentoxide. The constancy of the pressure during condensation indicated a high purity.

As stated in the discussion of carbon monoxide, Cardoso did practically all of the work alone during this particular period, and he had some difficulty in keeping the temperature constant while making his observations. His measurements of the temperature, which were made with a pentane thermometer, are open to question. The values of Onnes are therefore preferred.

The value for the critical density given by Mathias, Onnes, and Crommelin was obtained from the recilinear diameter by the usual method. 
26. NITROUS OXIDE

\begin{tabular}{|c|c|c|c|c|}
\hline Date & $t_{0}$ & $P_{0}$ & $d_{0}$ & Observers \\
\hline & ${ }^{\circ} \mathrm{C}$. & atm. & $g / c c$ & \multirow{7}{*}{$\begin{array}{l}\text { Janssen, Beibl. Ann. Physik., 2, p. 136; } 1878 . \\
\text { Dewar, Phil. Mag., 18, p. 210; 1884. } \\
\text { Cailletet and Mathias, Compt. rend., 102, p. 1202; } 1886 . \\
\text { Villard, Compt. rend., 118, p. 1096; 1894. J. phys., } \\
\text { p. 441; 1894. } \\
\text { Kuenen, Phil. Mag., 44, p. 195; 1897. } \\
\text { Cardoso and Arni, J. chim. phys., 10, p. 505; } 1912 .\end{array}$} \\
\hline $\begin{array}{l}1878 \ldots \\
1884 \ldots\end{array}$ & $\begin{array}{r}36.4 \\
* 35.4\end{array}$ & $\begin{array}{l}73.07 \\
* 75\end{array}$ & & \\
\hline $1886=$ & & & 0.41 & \\
\hline $1894 \ldots$ & 38.8 & 77.5 & .454 & \\
\hline $\begin{array}{l}1897 \ldots \\
1912 \ldots\end{array}$ & 36 & 71.9 & & \\
\hline $\begin{array}{l}1912 \\
\text { Selected values }\end{array}$ & $\begin{array}{l}36.5 \\
36.5\end{array}$ & $\begin{array}{l}71.65 \\
71.7\end{array}$ & $45 ?$ & \\
\hline Selected values & 36.5 & 71.7 & & \\
\hline
\end{tabular}

The nitrous oxide prepared by Villard was evidently very pure judging from the regularity of the phenomena obtained near the critical point, but his values for the critical termperature and density were obtained indirectly by measuring the densities of the liquid and gas phases. He does not discuss his method of measuring the critical pressure.

Kuenen purified commercial nitrous oxide by passing it over calcium chloride, caustic potash, and phosphorus pentoxide, after which it was liquefied and distilled. An increase in pressure of 0.30 per cent on condensation at constant temperature indicates a slight impurity.

The samples used by Cardoso and Arni were prepared from hydroxylamine hydrochloride and sodium nitrite solution and were purified by means of potassium hydroxide solution, sulphuric acid, and finally phosphorus pentoxide. The sample thus obtained was fractionally distilled 10 times. Their values are no doubt the best. Because of the apparently high purity of his nitrous oxide preference is given to Villard's value for the critical density. More data, however, are needed to corroborate this figure.

27. OXYGEN

\begin{tabular}{|c|c|c|c|c|}
\hline Date & $t_{\mathrm{o}}$ & $P_{0}$ & $d_{0}$ & Observers \\
\hline & & atm. & $g / c c$ & \multirow{10}{*}{$\begin{array}{l}\text { Sarrau, Compt. rend., 94, p. 639; } 1882 . \\
\text { Wroblewski, Compt. rend., 97, p. 309; } 1883 . \\
\text { Dewar, Phil. Mag., 18, p. 210; 1884. } \\
\text { Wroblewski, Ann. Physik., 25, p. 401; } 1885 . \\
\text { Olszewski, Phil. Mag., 39, p. 210; 1895. Compt. rend., } \\
\text { 100, p. 350; 1885. } \\
\text { Mathias, "Le point critique des corps purs," Paris; } 1904 . \\
\text { Dewar, Proc. Roy. Soc. London, 73, p. 251; } 1904 . \\
\text { Happel, Physik. Z., 8, p. 204; 1907. } \\
\text { Mathias and Onnes, Comm. Leyden No. 117; } 1911 . \\
\text { Proc. Acad. Sci. Amsterdam, 13; 1911. Ann. phys., } \\
\text { 17, p. 416; 1922. } \\
\text { Onnes, Dorsman, and Holst, Proc. Acad. Sci. Amster- } \\
\text { dam, 17, 1915; Comm. Leyden, 145b; 1914. } \\
\text { Cardoso, J. chim. phys., 13, p. 312; 1915. }\end{array}$} \\
\hline $1882 \ldots$ & $\begin{array}{l}-105.4) \\
-113\end{array}$ & (48.7) & $(0.3637)$ & \\
\hline 1884 & ${ }^{*}-113.0$ & 50 & $(.63)^{--}$ & \\
\hline 1885 & $\begin{array}{l}-118 \\
-118.8\end{array}$ & $\begin{array}{l}50 \\
50.8\end{array}$ & (2) & \\
\hline & & & $\begin{array}{l}(.400) \\
.4407\end{array}$ & \\
\hline 1907 & & & (. .433) & \\
\hline 1911_.. & & 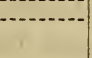 & .4299 & \\
\hline 1914 & -118.83 & 49. 71 & & \\
\hline Selected values. & $\begin{array}{l}-118.0 \\
-118.8\end{array}$ & $\begin{array}{l}49.30 \\
49.7\end{array}$ & $.430^{\circ}$ & \\
\hline & & & & \\
\hline
\end{tabular}

Only two determinations of the critical temperature and pressure of oxygen have been made since 1885 , one by Onnes, Dorsman, and Holst and one by Cordoso, both published about the same time. 
The oxygen used by Onnes, Dorsman, and Holst was prepared by heating pure recrystallized potassium permanganate in an apparatus made entirely of glass and passing the gas over heated platinized asbestos. The oxygen was then condensed by means of liquid air and allowed to slowly evaporate, thereby eliminating carbon dioxide and water vapor. The sample showed a constant pressure while being condensed at constant temperature. The pressures above 20 atmospheres were measured by means of a closed hydrogen manometer. As the critical point Onnes and his coworkers took the point at which, when the gas was slightly expanded, the meniscus appeared half way up the tube, and at which conversely, as the temperature reestablished itself, it disappeared again at the same level. They looked particularly for the critical opalescence but failed to find it. The value for the critical density was obtained from the rectilinear diameter.

Cordoso also prepared oxygen from pure crystallized potassium permanganate and passed the gas over solid potassium hydroxide, phosphorus pentoxide, and then through a Liebig bulb with mercury to decompose the ozone.

In consideration of the excellent means which Onnes and his coworkers had at their disposal for making these measurements preference is given, as in the case of nitrogen, to his results.

\section{PHOSGENE}

\begin{tabular}{|c|c|c|c|c|}
\hline Date & $t_{0}$ & $P_{0}$ & $d_{0}$ & Observers \\
\hline 1919 & $\begin{array}{r}{ }^{\circ} C_{\text {i83 }} \\
\quad 182\end{array}$ & atm. & $\begin{array}{l}g / c c \\
0.52\end{array}$ & \multirow{2}{*}{$\begin{array}{l}\text { Hackspill and Mathieu, Bull. soc. chim., } 25, \text { p. } 482 ; 1 y 19 \text {; } \\
\text { Germann and Taylor, J. Am. Chem. Soc., 48, p. 1154; } \\
\text { 1926. }\end{array}$} \\
\hline Selected values. & 182 & 56 & .52 & \\
\hline
\end{tabular}

Hackspill and Mathieu removed sulphur compounds from the commercial product by fractional distillation and eliminated most of the chlorine by contact with mercury for 24 hours. Final traces of chlorine were removed by distillation. The sealed tube containing the phosgene was placed in a hole in the center of a cylindrical aluminum block which could be heated electrically. The sample could be observed through a slot in the block. The temperatures were measured by means of a thermometer placed in another hole near the center of the block. Measurements indicated that the temperatures at this point and at the place occupied by the tube containing the gas could be maintained equal within $0.1^{\circ}$.

The purity of the sample is not established, however, and the method, while suitable for making approximate determinations at these temperatures, is not accurate. 
Germann and Taylor purified technical phosgene by repeated fractional distillation, following a preliminary chemical purification. The gas was not entirely pure, however, inasmuch as it could not be entirely liquified at constant pressure.

The Cailletet method (see discussion of ethane) was used for determining the critical point, the temperature being measured by an Anschütz-type thermometer which had been calibrated to tenths of a degree by the Bureau of Standards.

While the critical temperature was found to be between 181.7 and $181.8^{\circ}$, Germann and Taylor, in view of the work of Hackspill and Mathieu, adopted the rounded value $182^{\circ}$. The observed critical pressure was 55.3 atmospheres, while that calculated from the vaporpressure data is 55.6 atmospheres. The value adopted is 56 atmospheres.

No density measurements were made, but from the determinations of the densities of coexisting phases at high temperatures by Paternò and Mazzucchelli ${ }^{24}$ and two values at 25 and $0^{\circ}$ by Germann, ${ }^{25}$ an equation for the rectilinear diameter was obtained which yielded 0.52 for the critical density.

The values of Germann and Taylor are accepted rather than that of Hackspill and Mathieu because of the greater accuracy of the methods used.

\section{PROPANE}

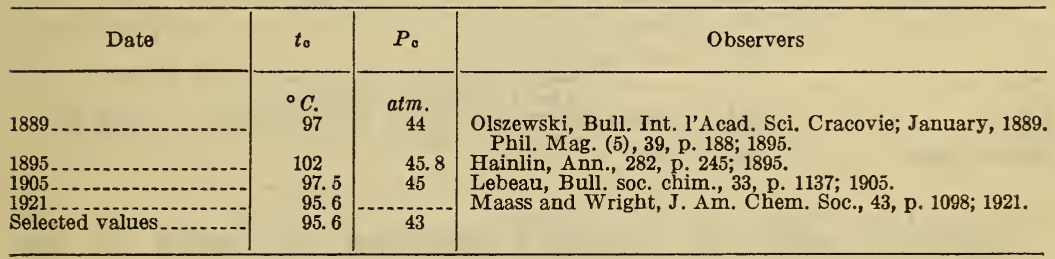

Hainlin apparently made no effort to purify his sample of propane, which he prepared by heating propyl iodide with aluminum chloride for 20 hours at $130^{\circ} \mathrm{C}$. His test for purity, which consisted of an analysis of the gas by exploding with oxygen, did not necessarily prove the absence of impurities. The observations of the critical phenomena were made in a sealed tube, the critical pressure being obtained from the vapor pressure data. Hainlin observed that as the temperature was raised the meniscus became indistinct at $101^{\circ}$, and that at $110^{\circ}$ all optical difference between the liquid and gas disappeared. Upon cooling, the critical opalescence appeared at $102^{\circ}$, which he selected as the critical temperature. 
Lebeau prepared propane by allowing propyl or isopropyl iodide to react with a solution of sodium in liquid ammonia. No criteria of purity are given. The critical temperature was determined both by the Cailletet method (see discussion of ethane) and by the sealedtube method.

Maass and Wright obtained propane by the action of a zinc-copper couple on propyl iodide. The gas was purified by passing through spirals cooled to $-78^{\circ} \mathrm{C}$, then a number of times over the zinccopper couple moistened with alcohol at $50^{\circ}$ until free from iodide, then through concentrated silver nitrate and concentrated alkali solutions, and was finally dried by phosphorus pentoxide and condensed. The propane was further purified by five distillations in a partial vacuum, the middle portions being retained in each instance. The method of determining the critical temperature is not described.

The value obtained by these authors is preferred to that obtained by Lebeau because of the precautions taken to insure the purity of the sample. On the other hand, the value for the critical pressure determined by Lebeau is probably more accurate than the values published by Olszewski and by Hainlin. The correction for the value of the critical pressure is 0.9 atmosphere per degree.

30. PROPYLENE

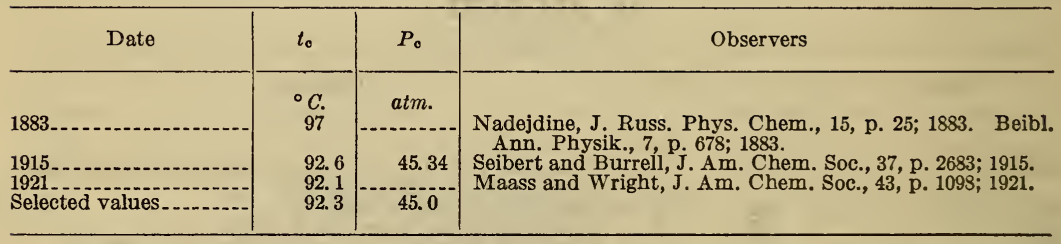

Nadejdine makes no statement regarding the purity of the propylene which he used.

Seibert and Burrell obtained propylene by dehydrating propyl alcohol with phosphorus pentoxide, collected the gas over caustic potash, and purified it by fractionation at low temperatures. The critical temperature was taken as that at which a meniscus, absent at constant volume, appeared when the volume was slightly increased. The pressures were measured by a calibrated air manometer.

The propylene used by Maass and Wright was prepared by the catalytic action of aluminum oxide upon purified propyl alcohol at a temperature of $350^{\circ} \mathrm{C}$. The gas was purified by the methods used by them in the case of ethylene.

The value selected for the critical temperature is the mean of the results of these two sets of observations. The correction for the value of the critical pressure is 0.9 atmosphere per degree. 


\section{SULPHUR DIOXIDE}

\begin{tabular}{|c|c|c|c|c|}
\hline Date & $t_{0}$ & $P_{0}$ & $d_{0}$ & Observers \\
\hline $\begin{array}{l}1859 \\
1878 \\
1879 \\
1882 \\
1887 \\
1903 \\
1906 \\
1907 \\
1912 \\
1912 \\
\text { Selected values. }\end{array}$ & $\begin{array}{l}{ }^{\circ} C . \\
157.0 \\
157-161 \\
{ }^{*} 155.4 \\
{ }^{*} 155.0 \\
{ }^{*} 155.4 \\
156.0 \\
157.26 \\
157.2 \\
157.3 \\
157.15 \\
157.6 \\
157.14 \\
157.2\end{array}$ & $\begin{array}{c}\text { atm. } \\
78.9 \\
778.9 \\
77.95 \\
77.65 \\
77.7\end{array}$ & $\begin{array}{c}g / c c \\
0.52 \\
\\
\\
\\
\end{array}$ & $\begin{array}{l}\text { Drion, Ann. chim. phys., 56, p. 221; } 1859 . \\
\text { Ladenburg, Ber., 11, p. 818; 1878. } \\
\text { Sajotsehewskl, Beibl. Ann. Physik., 3, p. 741; } 1879 . \\
\text { Schuck, Beibl. Ann. Physik., 6, p. 86; } 1882 . \\
\text { Dewar, Phil. Mag., 18, p. 210; 1884. } \\
\text { Cailletet and Mathias, Compt. rend., 104, p. 1563; } 1887 \\
\text { Centnerszwer, Z. physik. Chem., 46, p. 472; } 1903 . \\
\text { Briner, J. chim. phys., 4, p. 474; } 1906 . \\
\text { Travers and Usher, Z. physik. Chem., 57, p. 365; } 1007 . \\
\text { Cardoso and Bell, J. chim. phys., 10, p. 502; } 1912 . \\
\text { Niggli, Z. anorg. Chem., 75, p. 161; 1912. } \\
\text { Hein, Z. physik. Chem., 86, p. 409; 1913. }\end{array}$ \\
\hline
\end{tabular}

The values for the critical temperature of sulphur dioxide obtained since 1887 agree remarkably well with the exception of that of Niggli, none of the five deviating more than $0.1^{\circ}$ from the mean of $157.2^{\circ}$. This figure can, therefore, be taken as being accurate to the nearest tenth degree.

Of the two recent determinations of the critical pressure, preference is given to that of Cardoso and Bell, because their description shows that the work was carefully carried out, while Briner does not discuss his apparatus or method.

The only value for the critical density is that of Cailletet and Mathias, which was obtained in 1887 and can not be accepted as very reliable.

32. XENON

\begin{tabular}{|c|c|c|c|c|}
\hline Date & $t_{0}$ & $P_{0}$ & $d_{0}$ & Observers \\
\hline $1901 \ldots$ & ${ }^{\circ} C$. & $\stackrel{\text { atm. }}{\quad .0}$ & $g / c c$ & \multirow{3}{*}{$\begin{array}{l}\text { Ramsay and Travers, Trans. Roy. Soc. (London), A197, } \\
\text { p. } 71 ; 1901 . \\
\text { Patterson, Cripps, and Whytlaw-Gray, Proc. Roy. Soc. } \\
\text { (London), 86A, p. 579; } 1912 \text {. }\end{array}$} \\
\hline $1912 \ldots \ldots \ldots$ & 16.6 & 58.2 & 1.155 & \\
\hline Selected values_- & 16. 6 & 58.2 & 1.155 & \\
\hline
\end{tabular}

Ramsay and Travers make no claim for a high degree of accuracy in their determinations of the critical constants of xenon because they had only $3 \mathrm{cc}$ of gas, giving $0.006 \mathrm{cc}$ of liquid, and were, therefore, unable to get complete purification.

From Ramsay and Moore, Patterson and his coworkers procured 120 cc of impure xenon. After solidifying the gas and pumping off the noncondensible gases they distilled the xenon and took the last $20 \mathrm{cc}$ for their measurements. The temperatures were maintained constant to $0.02^{\circ}$. They noted that apparently unless certain precautions were taken xenon and oxygen would physically associate, and later dissociate, giving off oxygen which would lower the critical density. 


\section{CONCLUSION}

A résumé of the values which have been selected are given in Table 1. In the cases of those substances for which all three constants have been determined the molecular weights $M$ and the values of the expression $\frac{R T_{\mathrm{c}} d_{\mathrm{c}}}{M P_{\mathrm{c}}}$ are included, where $R$, the gas constant, is taken as 82.07 cc atmospheres per gram molecule, per degree. These values, it will be seen, vary from 3.00 for krypton to 4.12 for ammonia. From an examination of values for the monatomic gases it would appear that the critical constants of krypton are inaccurate, for the value of the expression $\frac{R T_{\mathrm{c}} d_{\mathrm{c}}}{M P_{\mathrm{c}}}$, should be about 3.5. On the other hand, the value 4.12 for ammonia is exceptionally high. In this instance, however, the explanation lies in the abnormality of the substance itself, for the critical constants of this substance are fairly accurately known.

Various equations of state yield values for $\frac{R T_{\mathrm{c}} d_{\mathrm{c}}}{M P_{\mathrm{o}}}$, which are constants for all gases. That computed from the equation of van der Waals, for example, is 2.67, while the equation of Dieterici gives 3.70, which agrees quite well with 3.523 , the mean of the values given in the table.

While this quantity varies with the different gases, it nevertheless will indicate any wide discrepancies in the values for the critical constants. 
TABLE 1.-The critical constants of various gases

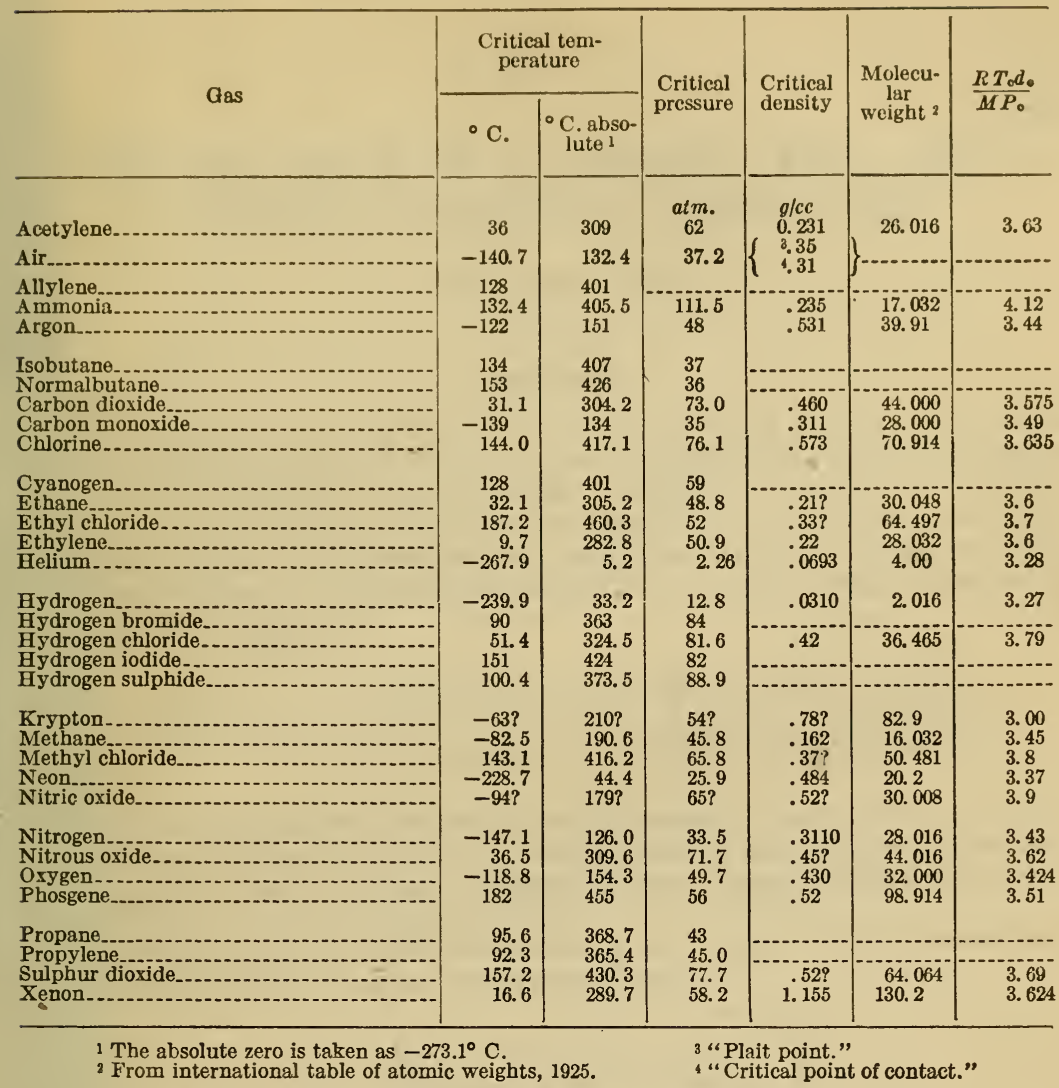

Nоте.-The figures followed by a question mark are considered unreliable.

WASHington, January 22, 1926. 



